\title{
手性膦小分子催化不对称反应的研究进展
}

\author{
唐 谦涂爱平双真真胡梦莹钟为慧* \\ (浙江工业大学药学院 绿色制药技术与装备教育部重点实验室 杭州 310014)
}

\begin{abstract}
摘要 手性膦小分子催化的不对称反应是目前研究的热点之一, 该类反应具有反应时间短、条件温和、催化活性高、 环境友好等优点, 符合绿色化学发展方向. 对手性膦小分子催化的不对称 Morita-Baylis-Hillman 反应、Morita-BaylisHillman 加成物的烯丙基位立体选择性取代反应、环加成反应、酯化反应， $\gamma$-加成反应以及其它重要的不对称反应进行 简要的评述.
\end{abstract}

关键词 手性膦小分子催化; Morita-Baylis-Hillman 反应; 不对称反应

\section{Progress in Enantioselective Phosphine Organocatalysis}

\author{
Tang, Qian $\quad \mathrm{Tu}$, Aiping $\quad$ Deng, Zhenzhen Hu, Mengying Zhong, Weihui* \\ (Key Laboratory for Green Pharmaceutical Technologies and Related Equipment of Ministry of Education, College of \\ Pharmaceutical Sciences, Zhejiang University of Technology, Hangzhou 310014)
}

\begin{abstract}
Enantioselective phosphine organocatalysis has been a research frontier in the field of asymmetric catalysis. The comparable advantages, including short reaction time, mild reaction conditions, high catalytic activity, and environment benign, render the organocatalytic reaction to meet the development direction of green chemistry. This paper briefly reviews the recent advances in the development of chiral phosphine-catalyzed asymmetric reactions, such as Morita-Baylis-Hillman reaction, the asymmetric allylic substitution of Morita-Baylis-Hillman adducts, cycloaddition, esterification reaction, $\gamma$-addition reaction and other asymmetric reaction.
\end{abstract}

Keywords enantioselective phosphine organocatalysis; Morita-Baylis-Hillman reaction; asymmetric reaction

现代合成化学、药物化学和材料科学的发展使人们 越来越认识到手性的重要性, 而不对称催化是获得光学 活性物质最有效的方法之一，提高反应的立体选择性的 关键在于设计和笁选合适的催化剂. 虽然有机金属催化 剂能有效催化多种不对称反应 ${ }^{[1]}$, 且具有较高的立体选 择性，但由于价格昂贵、金属残留以及回收套用等问题, 限制了有机金属催化剂在有机合成中的应用与发展. 与 有机金属催化剂相比, 有机小分子催化剂有许多独特的 性能: 反应条件温和、催化剂对环境友好、原料价格低 廉、反应体系无重金属残留等. 近年来, 手性有机小分 子催化剂的研究越来越受到广大研究者的重视, 在短短 几年的时间内便成为不对称催化研究领域的一个热点, 且被认为是继酶催化和手性金属络合物催化之后又一 类用途广泛的手性催化剂, 有学者称现在是 “手性有机 小分子催化的黄金时代”[2].
当然，非金属有机小分子催化剂的种类有很多 ${ }^{[3]}$, 其中手性膦催化是有机小分子手性催化中的重要组成 部分. 由于磷原子体积比较大, 可极化性大, 因此烷基 膦亲核性比较强，而碱性却远远弱于相应的胺. 如三烷 基膦的亲核性是三乙胺的 100 倍，而碱性仅是其 $1 \%{ }^{[4]}$, 因此叔膦作为 Lewis 碱常应用于亲核性有机催化反应 中. 叔膦的催化活性与膦上的孤对电子有关, 通过膦上 的孤对电子进攻亲电试剂形成新键, 之后亲核性膦释放 出来完成催化循环. 手性膦催化剂主要催化的反应有 Morita-Baylis-Hillman 反应(简称：MBH 反应), Morita-Baylis-Hillman 加成物(简称: MBH 加成物)的烯丙基 位取代反应，环加成反应，酯化反应， $\gamma$-加成反应以及其 它重要的不对称有机反应 ${ }^{[5]}$. 本文就对近年来手性膦小 分子催化不对称反应的研究进展做一简要评述.

\footnotetext{
*E-mail: weihuizhong@zjut.edu.cn

Received October 13, 2012; revised December 11, 2012; published online December 13, 2012.

Project supported by the National Natural Science Foundation of China (Nos. 21076194 \& 21276238).

国家自然科学基金(Nos. 21076194 \& 21276238 ) 资助项目.
} 


\section{1 不对称 Morita-Baylis-Hillman 反应}

\section{1 联䓫酚衍生的手性膦催化剂}

联荎酚是一类具有刚性的轴手性化合物, 但由于其 可以通过结构修饰和添加基团来改变其角度，也具有一 定的柔韧性. 该类光学活性的异构体及衍生物在不对称 催化合成中得到了广泛的应用, 当然在手性膦的构建中 也起到了举足轻重的作用.

1998 年, Soai 等 ${ }^{[6]}$ 首次报道了联萗酚衍生的 $S$-BINAP 应用于嘧啶醛参与的 $\mathrm{MBH}$ 反应, 产物收率和 $e e$ 值均较低(Eq. 1).

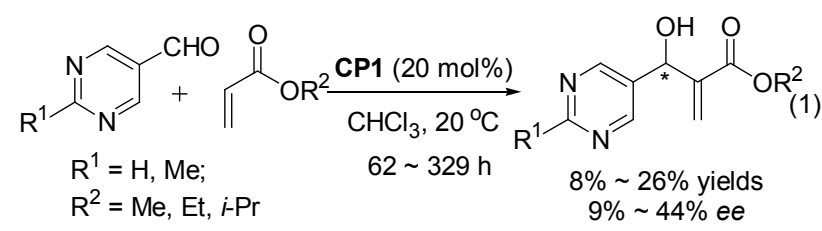<smiles>c1ccc(-c2ccc3ccccc3c2-c2c(-c3ccccc3)ccc3ccccc23)cc1</smiles>

CP1

2003 年, Shi 等 ${ }^{[7 a]}$ 首次将联菜酚衍生的双功能手性 膦催化剂用于催化 $N$-磺酰亚胺和丁烯酮的 aza-MBH 反 应, 得到较高的收率和优异的 $e e$ 值(Eq. 2). 当反应体系 在无水条件下进行时, 如加入分子笁, 反应收率有较大 提高, 而 $e e$ 值变化不大. 反应的可能机理 ${ }^{[7 b]}$ 如 Scheme 1 所示, 首先催化剂 CP2 上的膦进攻末端烯烃, 同时酚羟 基与羰基形成氢键, 得到关键的烯醇结构中间体 $\mathbf{A}$, 然 后与磺酰亚胺结合形成优势的非对映异构体, 得到反应 中间体 $\mathbf{B}$, 最后经质子转移和 $\beta$ 消除, 得到目标产物.

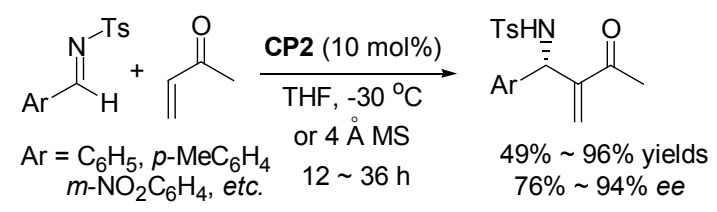<smiles>Oc1ccc2ccccc2c1-c1c(-c2ccccc2)ccc2ccccc12</smiles>

基于以上机理, 在后续的研究中, Shi 和 Sasai 等小 组分别进一步修饰催化剂 $\mathbf{C P}{ }^{[7 b]}$ (Scheme 2). 首先, 引 入更多的酚羟基, 得到新催化剂 $\mathrm{CP3}^{[8]}$ 和 $\mathrm{CP}^{\left[{ }^{[9]}\right.}$, 以增 加形成氢键的数量, 进而增强过渡态的稳定性, 从而提 高反应的收率及立体选择性. 2007 年, Ito 等 ${ }^{[10]}$ 设计了催

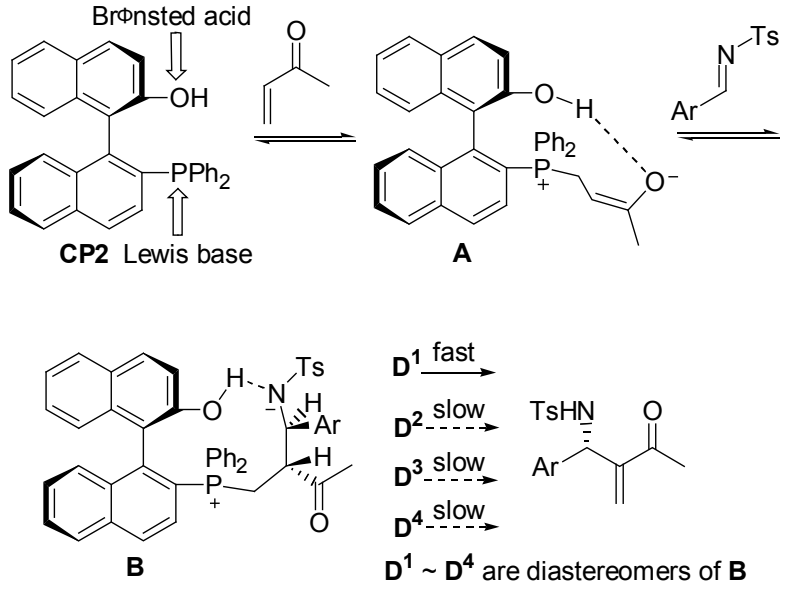

Scheme 1
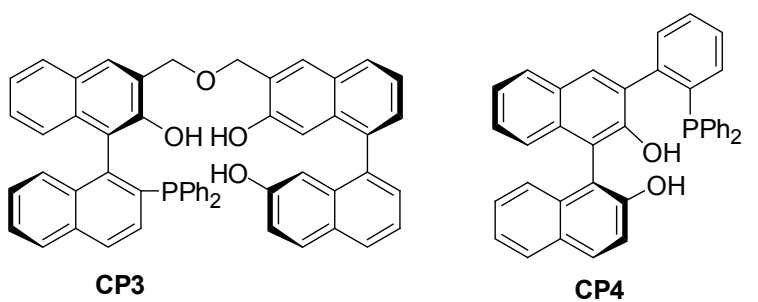

CP3<smiles>Oc1ccc2cc(CCC(F)(F)F)ccc2c1-c1c(-c2ccccc2)ccc2cc(CCC(F)(F)F)ccc12</smiles>

CP5

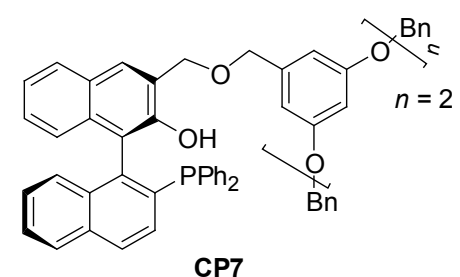

CP7

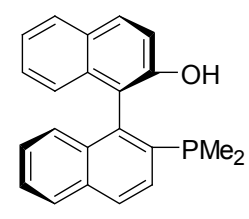

CP8

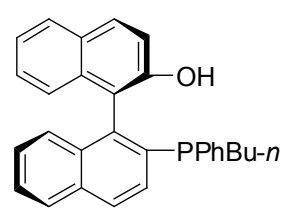

CP9
Scheme 2

化剂 CP5, 通过调节碳链的长度来考查催化剂的构效关 系，发现两个碳时其催化效果最好. 其次，试图引入大 基团，以增加空间位阻，来提高立体选择性. Shi 等 ${ }^{[11]}$ 先 后设计了催化剂 CP6 和催化剂 CP7, 在联萗酚衍生的双 功能手性膦催化剂中, 催化剂 CP7 是唯一可以回收套 用的. 最后是改变膦上的取代基, Shi 等 ${ }^{[12]}$ 设计了催化剂 CP8 和 CP9, 实验发现 CP8 不仅可以催化 aza-MBH 反 应，也可以催化 $\mathrm{MBH}$ 反应，但反应的立体选择性不高. 
2007 年, Shi 等 ${ }^{[13]}$ 在联荟酚骨架上引入氨基, 设计 合成了一系列硫脲类催化剂和酰胺类催化剂 (Scheme 3), 其中催化性能较好的是硫脲类催化剂 CP10、酰胺类 催化剂 CP11 和 CP12, 产物的 $e e$ 值为 35\% 97\%.<smiles>S=C(Nc1ccccc1)Nc1ccc2ccccc2c1-c1c(-c2ccccc2)ccc2ccccc12</smiles>
CP10<smiles>CC(=O)Nc1ccc2ccccc2c1-c1c(-c2ccccc2)ccc2ccccc12</smiles>
CP11<smiles>O=C(Nc1cc(-c2c(-c3ccccc3)ccc3ccccc23)c2ccccc2c1)c1cc(NC(=O)c2ccc3ccccc3c2-c2c(-c3ccccc3)ccc3ccccc23)cc(C(=O)Nc2ccc3ccccc3c2-c2c(-c3ccccc3)ccc3ccccc23)c1</smiles>

Scheme 3

2009 年, Liu 等 ${ }^{[14]}$ 首次报道了将具有 Lewis 碱、 Brønsted 酸和酸活化的 Brønsted 碱的三功能手性膦催化 剂应用到 aza-MBH 反应(Eq. 3). 实验发现室温下反应, 产物的收率和 $e e$ 值均较高, 但反应的主要不足是添加 剂苯甲酸的用量偏高.

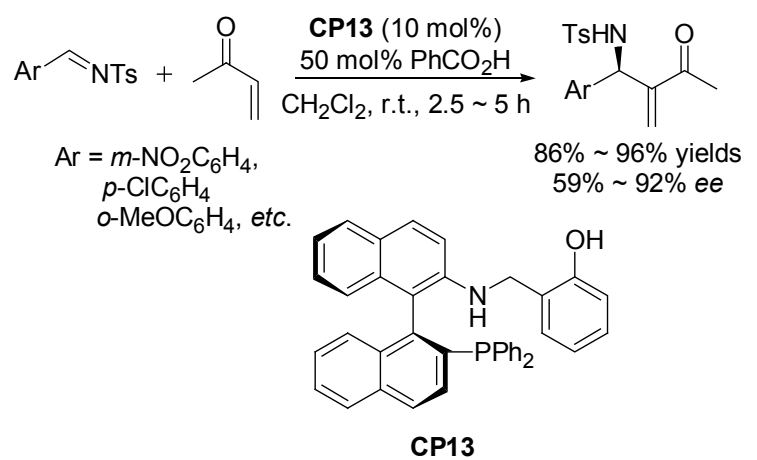

之后 Sasai 等 ${ }^{[15]}$ 对反应底物进行了拓展, 首次利用 手性催化剂 CP2 催化 aza-MBH 多米诺反应合成异吲哚 㕲类衍生物(Eq. 4). 该反应设计巧妙, 同时产物也得到 了较高的收率和良好的 $e e$ 值.

\section{2 氨基酸衍生的手性膦催化剂}

由于小分子手性氨基酸作为手性来源，具有价廉、 易得等特点. 近年来关于氨基酸衍生的双功能手性膦催 化剂的报道逐渐增加. 与联荎酚衍生的双功能手性膦催

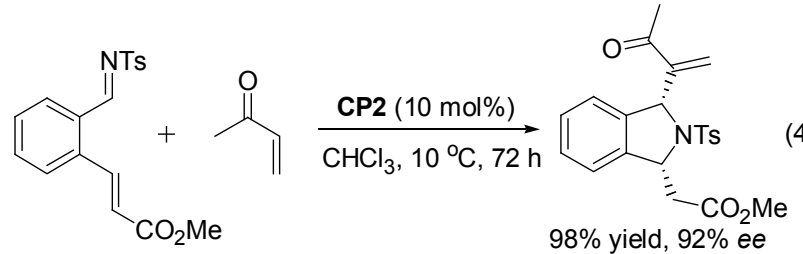

化剂相比，该类催化剂在催化 $\mathrm{MBH}$ 反应、环加成反应 中都具有较高活性，且获得了很好的收率和立体选择 性.

2009 年, $\mathrm{Wu}$ 等 ${ }^{[16]}$ 报道了烦氨酸衍生的手性膦用于 催化 $\mathrm{MBH}$ 反应(Eq. 5). 研究表明, 室温下反应得到的目 标产物的收率可达 $96 \%$, 且 $e e$ 值最高可达 $83 \%$.

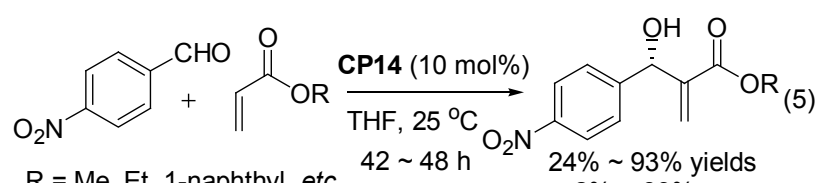

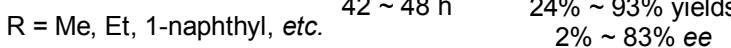<smiles>CC(C)[C@H](Cc1ccccc1)NC(=S)Nc1ccccc1</smiles>

2011 年, $\mathrm{Lu}$ 等 ${ }^{[17]}$ 报道了苏氨酸衍生的双功能手性 膦催化剂催化的 aza-MBH 反应，具有反应收率高和立 体选择性好等优点(Eq. 6).<smiles>[R]C=NS(=O)(=O)c1ccc(OC)cc1</smiles>

$\mathrm{R}=\mathrm{C}_{6} \mathrm{H}_{5}, 4-\mathrm{ClC}_{6} \mathrm{H}_{4}$, 2-furyl, 2-naphthyl, etc.

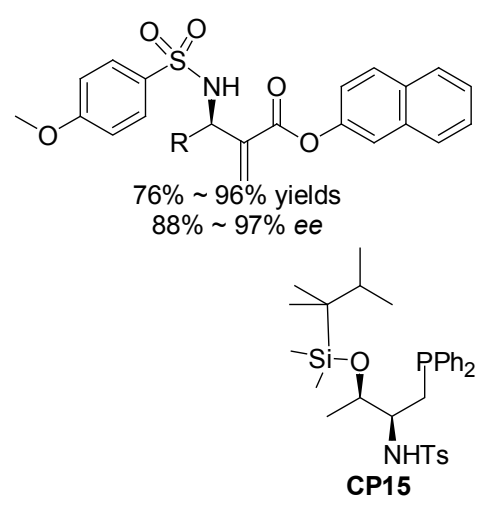

同年， $\mathrm{Lu}$ 等 ${ }^{[18]}$ 又将苏氨酸衍生的双功能手性膦催 化剂拓展到 $\mathrm{MBH}$ 反应，得到的 $\mathrm{MBH}$ 加成物 $e e$ 值最高 可达 90\% (Eq. 7).

\section{3 环己基衍生的手性膦催化剂}

2008 年 $\mathrm{Wu}$ 等 ${ }^{[19 a]}$ 报道了环已基衍生的双功能手性 


$$
\begin{aligned}
& \stackrel{\mathrm{R}}{\mathrm{OMe}}_{\mathrm{THF}, \text { r.t., } 42 \sim 96 \mathrm{~h}}^{\mathrm{CP16}(10 \mathrm{~mol} \%)} \\
& \mathrm{R}=3-\mathrm{NO}_{2} \mathrm{C}_{6} \mathrm{H}_{4}, 4-\mathrm{ClC}_{6} \mathrm{H}_{4} \\
& \text { 2-naphthyl, 3-pyridine, etc. } \\
& 25 \% \sim 92 \% \text { yields } \\
& 69 \% \sim 90 \% \text { ee }
\end{aligned}
$$

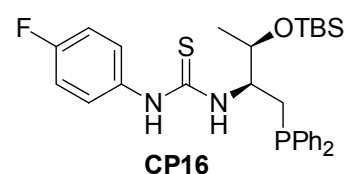

膦硫嫝催化 $\mathrm{MBH}$ 反应(Eq. 8). 研究表明, 该反应具有反 应条件温和、收率和对映选择性较高等优点. 2009 年, $\mathrm{Wu}$ 等 ${ }^{[19 b]}$ 又报道了类似的反应, 在催化剂 CP18 的催化 下，反应得到了良好的收率和中等的 $e e$ 值(Eq. 9).

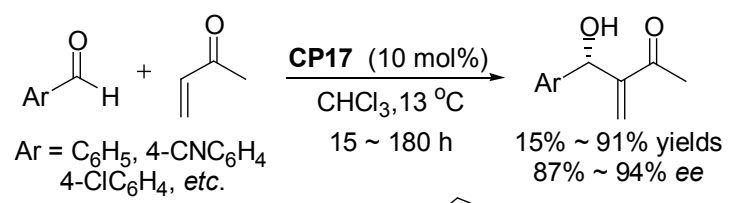

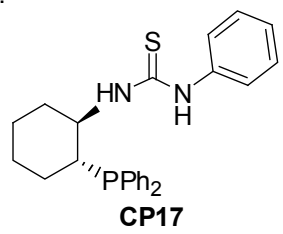

Ar $\stackrel{\mathrm{O}}{\mathrm{OR}}_{\mathrm{H}}^{\mathrm{CP} 18(8 \mathrm{~mol} \%)} \underset{\mathrm{THF}, 25^{\circ} \mathrm{C}, 5 \sim 24 \mathrm{~h}}{\mathrm{O}}$

$$
\begin{array}{cc}
\mathrm{Ar}=\mathrm{C}_{6} \mathrm{H}_{5}, 4-\mathrm{NO}_{2} \mathrm{C}_{6} \mathrm{H}_{4} & 24 \% \sim 94 \% \text { yields } \\
4-\mathrm{ClC}_{6} \mathrm{H}_{4} \text {, etc. } & 7 \% \sim 77 \% \text { ee }
\end{array}
$$

$\mathrm{R}=\mathrm{Et}, n-\mathrm{Bu}$

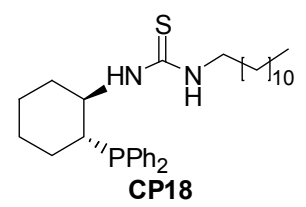

2011 年, $\mathrm{Wu}$ 等 ${ }^{[20]}$ 利用环己基衍生的双功能手性膦 硫嫝催化剂 CP17 催化吲哚醌为底物的 MBH 反应(Eq. 10). 在 $0{ }^{\circ} \mathrm{C}$ 下, 以四氢呋喃作溶剂, 该反应取得了 15\% 99\%收率和 9\% 69\% ee 值. 其 $\mathrm{MBH}$ 加成产物与 天然产物生物碱中的 convolutamydines B, convolutamydines E, dioxibrassinine 和 donaxaridine 具有类似的结 构 $^{[21]}$ (Scheme 4), 通过一定的结构修饰可应用于天然产 物的全合成. 最近, $\mathrm{Wu}$ 等 ${ }^{[22]}$ 又制备了新型催化剂 CP19 (Eq. 10). 实验发现, 在 $2 \mathrm{~mol} \%$ 的 CP19 催化下，室温下 反应得到产物的 $e e$ 值最高可达 $95 \%$.

另外 $\mathrm{Wu}$ 等 ${ }^{[23]}$ 将方酸结构引入到催化剂中形成新型 双功能手性膦催化剂 CP20 (Eq. 11). 研究表明, 在室温 下, CP20 可高效催化分子内的 $\mathrm{MBH}$ 反应, 且以高收率 和高立体选择性获得目标化合物.<smiles>[R1][Y17]1ccc2c(c1)N([R2])C(=O)C2=O</smiles>

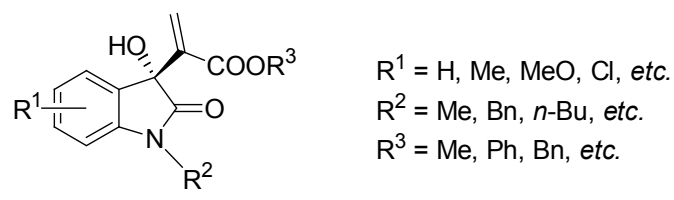<smiles>O=c1c(Nc2ccc([N+](=O)[O-])cc2)c(N[C@H]2CCCC[C@@H]2Pc2ccccc2)c1=O</smiles><smiles>[R]C[C@@]1(O)C(=O)Nc2cc(Br)cc(Br)c21</smiles>

Scheme 4

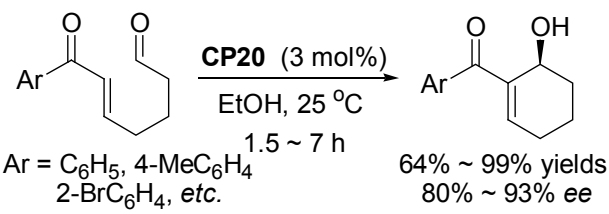<smiles>CCOc1c(NC2CCCCC2Pc2ccccc2)c(=O)c1=O</smiles>

CP20

\section{4 二茂铁衍生的手性膦催化剂}

近年来，绝大部分的手性膦二茂铁都作为金属不对 称催化反应的配体，很少有将其应用到手性小分子催化 上. 2005 年, Carretero 等 ${ }^{[24]}$ 将手性膦二茂铁应用到催化 不对称 $\mathrm{MBH}$ 反应, 得到了较高收率和中等 $e e$ 值的 $\mathrm{MBH}$ 产物(Eq. 12). 尽管该类催化剂的催化效果不是很 理想, 但还有相当大的提升空间. 因此, 这一课题值得 广大研究者进一步深入研究.

\section{$2 \mathrm{MBH}$ 加成物的烯丙基立体选择性取代反应}

关于手性膦催化 $\mathrm{MBH}$ 加成物的烯丙基立体选择性 取代反应的研究报道较晚 ${ }^{[25]}$, 直到 2004 年, Krische 等 [26]首次报道了有机膦催化 $\mathrm{MBH}$ 加成物的烯丙基位立体 选择性取代反应，并提出了可能的机理(Scheme 5). 


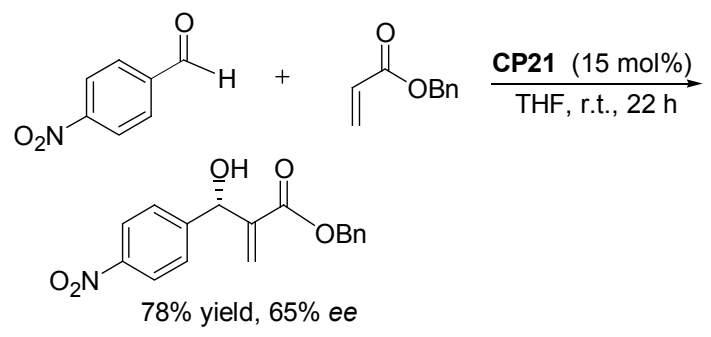
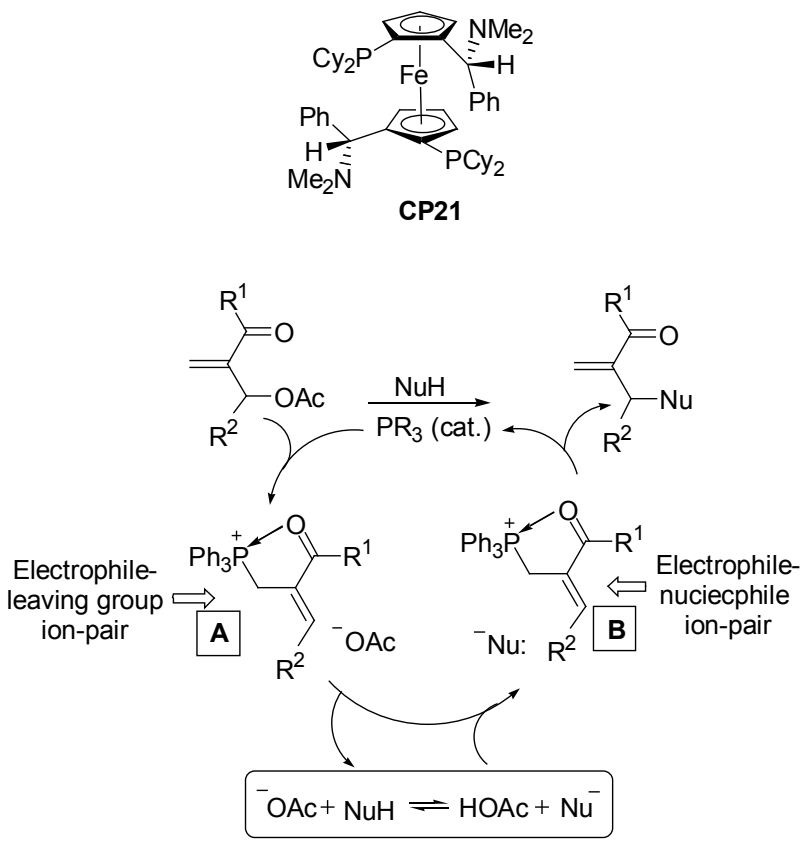

Scheme 5

受 Krische 课题组在 MBH 醋酸酯上构建 $\gamma$-丁烯酸 内酯的启发, 侯雪龙课题组和施敏课题组对 MBH 加成 物不对称转化进行了深入研究. 2007 年, 侯雪龙等 ${ }^{[27]}$ 利 用具有平面手性的 [2,2]环芳单膦催化剂 CP22 催化邻苯 二甲酰亚胺取代 MBH 加成物烯丙基位的反应, 得到了 具有较好立体选择性的产物, 但反应底物的适用范围较 窄(Eq. 13).<smiles>C=C(C(=O)OC)C(OC(C)=O)c1ccc([N+](=O)[O-])cc1</smiles><smiles>C=C(C(=O)OC)C(c1ccc([N+](=O)[O-])cc1)N1C(=O)c2ccccc2C1=O</smiles>

$95 \%$ yield, $71 \%$ ee

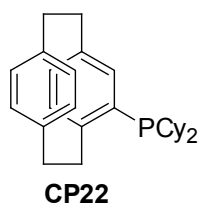

2008 年, Shi 等 ${ }^{[28]}$ 报道了双功能手性膦催化 2-三甲 硅氧基呋喃立体选择性取代 MBH 加成物的反应，形成 了具有 $\gamma$-丁烯酸内酯结构的化合物(Eq. 14), 该反应篎 选了一系列双功能化手性膦催化剂, 其中 CP11 的催化 效果最好. 作者通过 ${ }^{31} \mathrm{P}$ NMR 观察到反应的中间体，并 推测催化剂与底物形成的中间体通过分子间氢键产生 稳定的过渡态构象.

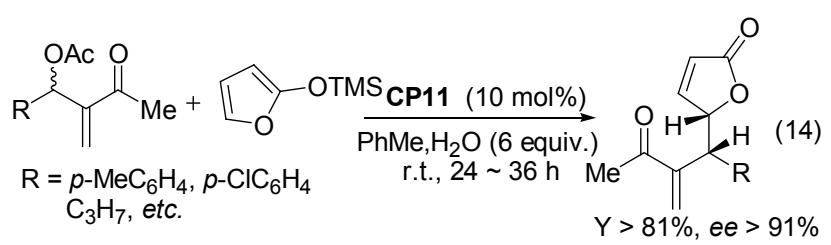<smiles>CC(=O)Nc1ccc2ccccc2c1-c1c(-c2ccccc2)ccc2ccccc12</smiles>

2009 年, Shi 等 ${ }^{[29]}$ 也对邻苯二甲酰亚胺立体选择性 取代 $\mathrm{MBH}$ 加成物烯丙基位的反应进行了研究(Eq. 15). 结果表明，催化剂 CP23 可高效催化该反应，得到了高 收率和中等 $e e$ 值的产物。

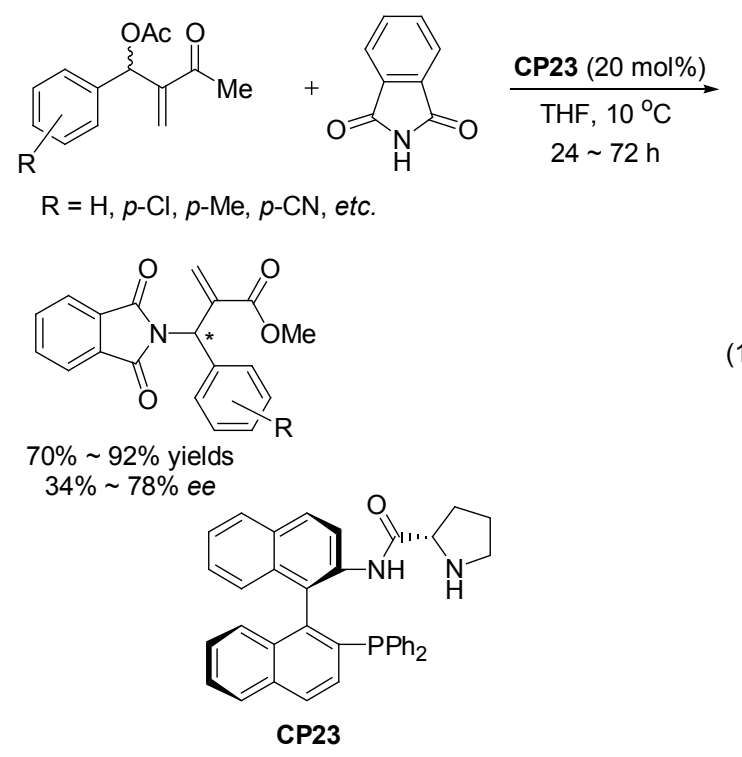

之后 Shi 等 ${ }^{[30]}$ 又对反应底物进行了拓展. 2011 年, 他们报道了双功能手性膦硫脲衍生物催化噁唑酮类化 合物与 $\mathrm{MBH}$ 加成物的 $\mathrm{S}_{\mathrm{N}} 1$ 反应(Eq. 16), 得到具有高收 率和高 $e e$ 值的对映选择性产物.

2012 年, Shi 等 ${ }^{[31]}$ 又将亚磷酸二苯酯和二苯基氧膦 作为亲核试剂与 $\mathrm{MBH}$ 加成物反应, 得到了较高收率和 高 $e e$ 值的目标产物(Eq. 17). 


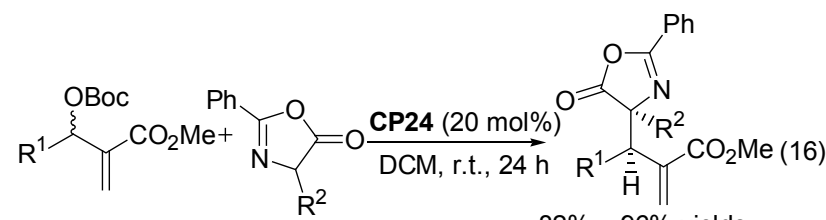
$\mathrm{R}^{1}=p-\mathrm{BrC}_{6} \mathrm{H}_{4}, o-\mathrm{MeC}_{6} \mathrm{H}_{4}$, Et, etc. $\quad 82 \% \sim 96 \%$ yields $\mathrm{R}^{2}=i-\mathrm{Pr}, i-\mathrm{Bu}, \mathrm{Me} \quad 3: 1 \sim 20: 1 d r$<smiles>Cc1cc(C)cc(P(c2cc(C)cc(C)c2)c2ccc3ccccc3c2-c2c(NC(=S)NCc3ccccc3)ccc3ccccc23)c1</smiles>

CP24

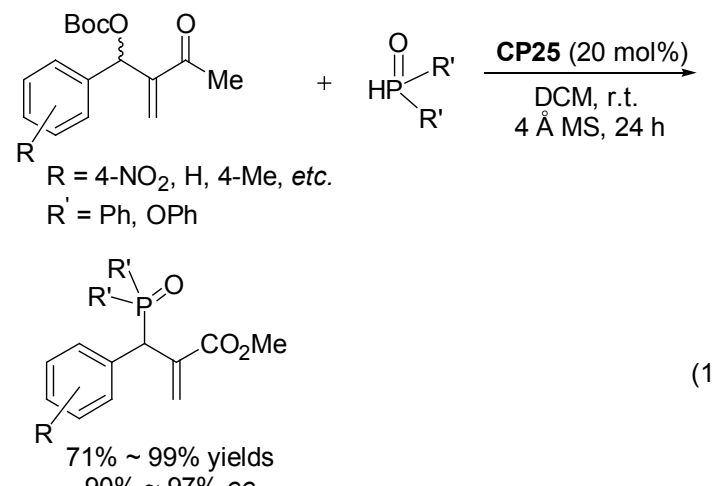<smiles>Oc1ccc2ccccc2c1[C@H](NC(=S)Nc1ccc2ccccc2c1-c1ccccc1)c1ccc2ccccc2c1-c1ccccc1</smiles>

同年, $\mathrm{Lu}$ 等 $^{[32]}$ 首次将苯酞类化合物作为亲核试剂 与 $\mathrm{MBH}$ 加成物进行立体选择性取代反应, 形成具有光 学纯的 3,3-双取代苯酞类化合物, 后者广泛存在于天然 产物和重要的生物分子中 (Scheme 6). 实验表明, 在双 功能手性膦硫脲催化剂促进下, 反应经历了 $\mathrm{S}_{\mathrm{N}} 2^{\prime}-\mathrm{S}_{\mathrm{N}} 2^{\prime}$ 的 反应机理, 得到高收率和高 $e e$ 值的 3,3-双取代苯酞类化 合物(Eq. 18).

\section{3 环加成反应}

\section{$3.1[2+2]$ 环加成反应}

2010 年 Kerrigan 等 ${ }^{[33]}$ 报道了以双膦催化剂 BINAPHANE (CP27)催化芳香醛与烯酮之间的[2+2]环加成反 应(Eq. 19), 得到了具有多手性中心的多取代 $\beta$-内酯类 化合物, 且其可能的机理如 Scheme 7 所示.

\section{$3.2[3+2]$ 环加成反应}

联烯、MBH 加成物与活性烯烃或亚胺的不对称 $[3+2]$ 环加成反应是一类非常重要的反应 ${ }^{[34]}$, 通过手性<smiles>COc1cc(O)c2c(c1)[C@@]1(CC(=O)O1)OC(=O)[C@]2(CC(C)=O)OC(=O)O</smiles>

(-)-Arnottin II

Altenuic acid II

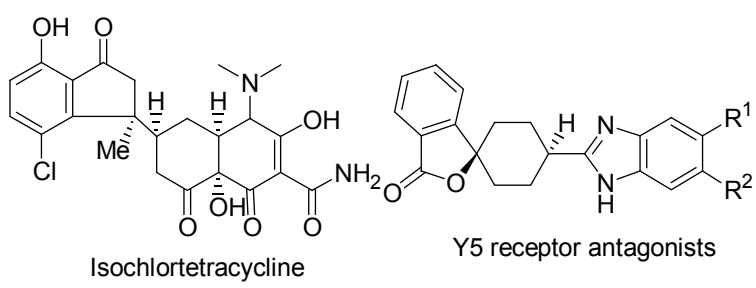<smiles>COC(=O)[C@]1(c2ccccc2)OC(=O)c2c1ccc1c2N(C)c2cccc(C(N)=O)c2N1</smiles>

Scheme 6

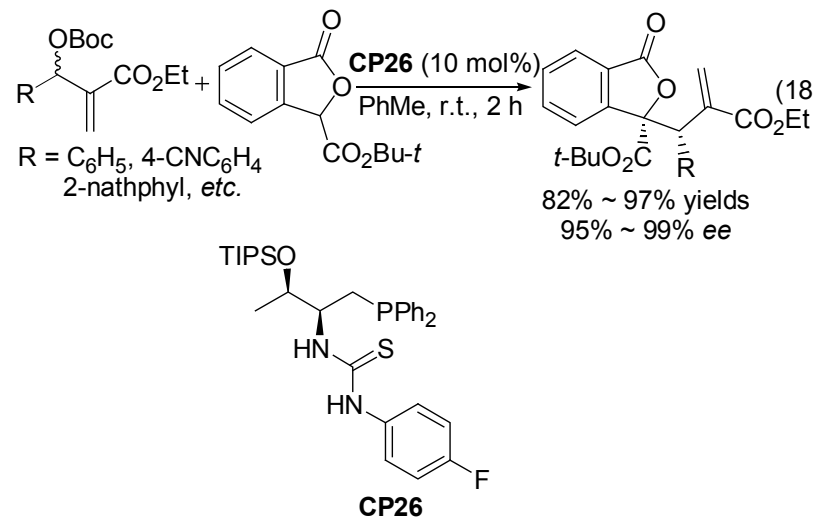

$$
\begin{array}{ll}
\mathrm{R}_{\mathrm{R}^{2}} & \\
\mathrm{R}^{1}=\mathrm{Ph} \text {, indolyl, 2-tolyl } & 51 \% \sim 99 \% \text { yield } \\
\mathrm{R}^{2}=\mathrm{Me}, \mathrm{Et}, n \text { - } \mathrm{Bu}, \mathrm{Ph} & 53: 47 \sim 99: 1 \mathrm{dr} \\
\mathrm{CH}_{2} \mathrm{Cl}_{2},-78{ }^{\circ} \mathrm{C}, 4 \mathrm{~h} &
\end{array}
$$$$
\mathrm{R}^{3}=\mathrm{Ph}, 4-\mathrm{ClC}_{6} \mathrm{H}_{4}, 4-\mathrm{NO}_{2} \mathrm{C}_{6} \mathrm{H}_{4} \text {, etc. }
$$

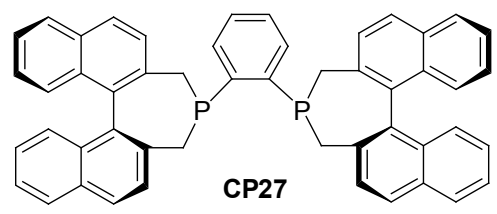

膦催化可有效构建具有光学活性的天然产物骨架结构.

\section{2 .1 手性单膦催化剂}

1995 年, $\mathrm{Lu}$ 等 ${ }^{[35]}$ 首次报道了有机膦催化缺电子烯 烃与联烯酸酯的 $[3+2]$ 环加成反应. 之后对反应底物进 行了拓展, 发现用富马酸酯、马来酸酯、丙烯酸酯、丁 烯酩、丙烯腈等, 得到的是非手性的多官能团环戊烯衍 


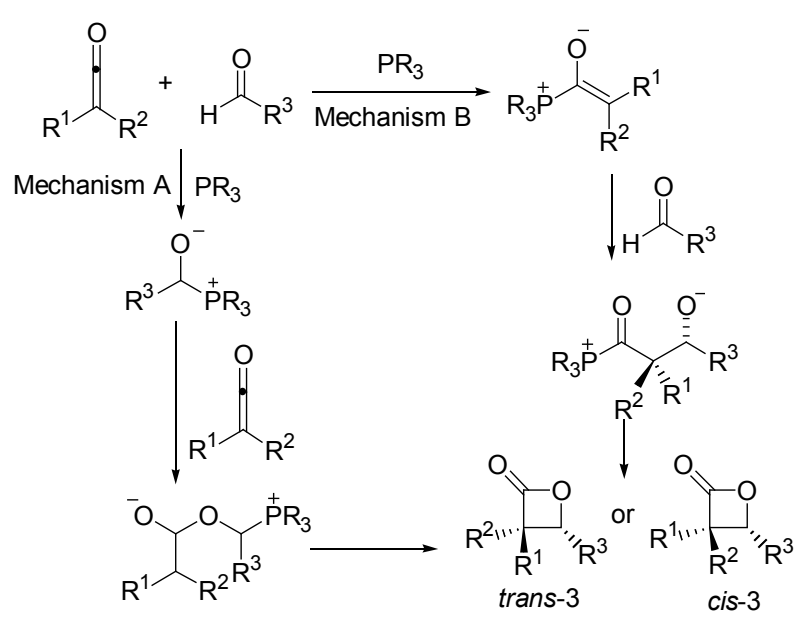

Scheme 7

生物. 1997 年, Zhang 等 ${ }^{[36]}$ 利用手性膦催化该反应(Eq. 20), 得到了具有较好对映选择性的目标产物.

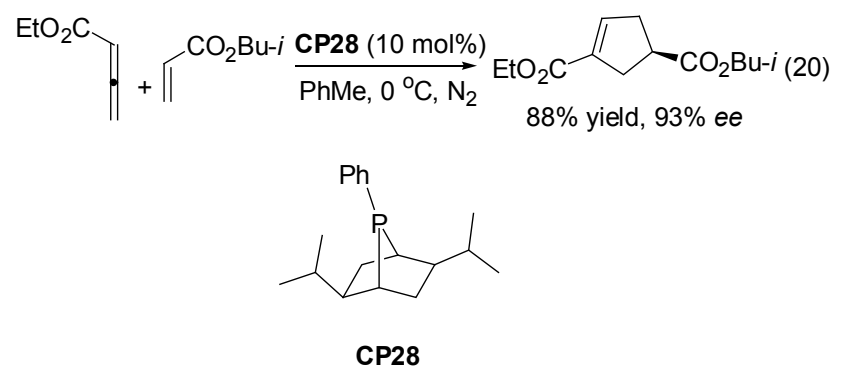

尽管取得了一些研究成果, 但之后十年有机膦催化 的不对称 $[3+2]$ 环加成反应并未取得较好的进展. 直到 2006 年 $\mathrm{Fu}^{[37]}$ 报道了手性单膦催化剂 CP29 催化的 $[3+2]$ 环加成反应(Eq. 21), 目标产物的 $e e$ 值可达 $90 \%$, 非对 映选择性> $20: 1.2008$ 年 Marinetti 等 ${ }^{[38 a]}$ 设计了催化剂 CP30 催化类似的反应(Eq. 21), 目标产物的 ee 值为 $87 \% \sim 96 \%$, 且催化剂稳定、可回收套用 ${ }^{[38 b]}$. 之后催化 剂 CP30 又被证明可高效催化联烯磷酸酯与缺电子烯烃 的 [3+2]环加成反应(Eq. 22), 产物的收率为 $60 \% \sim 87 \%$, 产物 $e e$ 值为 $45 \% \sim 91 \%{ }^{[39]} .2010$ 年 Marinetti 等 ${ }^{[40]}$ 首次 用 2-芳基-1,1-二氧基乙烯作为底物, 在手性膦催化剂 CP29 的作用下, 反应所得产物的收率较高, ee 值可达 $90 \%$ (Eq. 23).

手性单膦催化的 $[3+2]$ 环加成反应可应用于螺环类 化合物的合成. 2008 和 2009 年, Marinetti 等 ${ }^{[38 b]}$ 报道了手 性膦催化剂 CP30 催化[3+2]环加成反应(Eq. 24), 得到 的螺环衍生物的 $e e$ 值可达 $85 \% .2010$ 年, Marinetti 等 ${ }^{[41]}$ 又首次用手性磷催化剂高效构建了螺环吲哚酮环龙烷 衍生物(Eq. 25).

2011 年 Marinetti 等 ${ }^{[42]}$ 又报道了手性膦催化合成环 戊烯并香豆素或喹啉衍生物. 该反应通过两种合成途

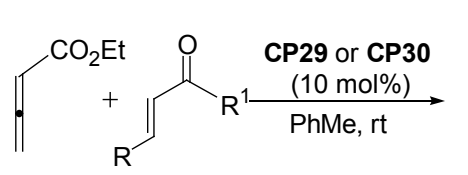

$\mathrm{R}=\mathrm{Ph}, 2$-furyl, 2-quinolyl, etc. $\mathrm{R}^{1}=\mathrm{Ph}, 4-\mathrm{MeOC}_{6} \mathrm{H}_{4}$, etc.<smiles>[R7]C(=O)C1=CCC(C([R7])=O)C1[R2]</smiles>

$39 \% \sim 76 \%$ yields $75 \% \sim 90 \%$ ee<smiles>CCCCCCCC(=O)OCc1ccc2ccccc2c1-c1c(CP)ccc2ccccc12</smiles>

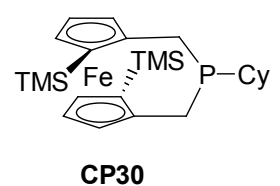

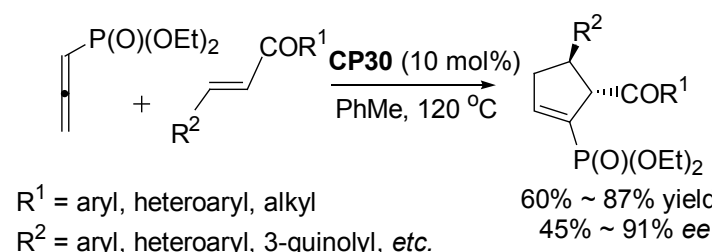

$\mathrm{R}^{1}=$ aryl, heteroaryl, alky $\mathrm{R}^{2}=$ aryl, heteroaryl, 3-quinolyl, etc
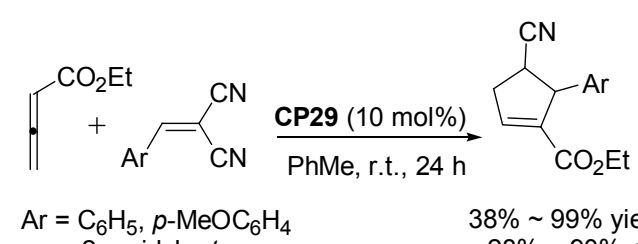
2-pyridyl, etc.

$38 \% \sim 99 \%$ yields $28 \% \sim 90 \%$ ee<smiles>[R]OC(=O)/C=C\[CH+]Br</smiles>

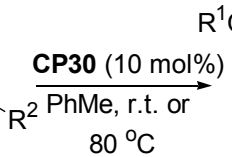

$\mathrm{R}^{1} \mathrm{O}_{2} \mathrm{C} \mathrm{O}$

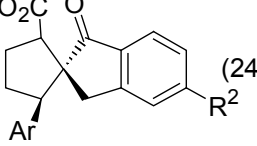

$\mathrm{R}^{1}=\mathrm{Et}, \mathrm{Cy}, \mathrm{Bn}$

$20 \mathrm{~h}$

$\mathrm{R}^{2}=\mathrm{Br}, \mathrm{H}, \mathrm{Me}$

$\mathrm{Ar}=\mathrm{Ph}, 4-\mathrm{ClC}_{6} \mathrm{H}_{4}$, 1-naphthyl<smiles>[R]C=C1C(=O)N([Y6])c2ccccc21</smiles>

CP29 or CP30

(10 mol\%)

PhMe, r.t., $18 \mathrm{~h}$

$\mathrm{R}^{2}=$ aryl, heteroaryl, 2-quinolyl, etc.

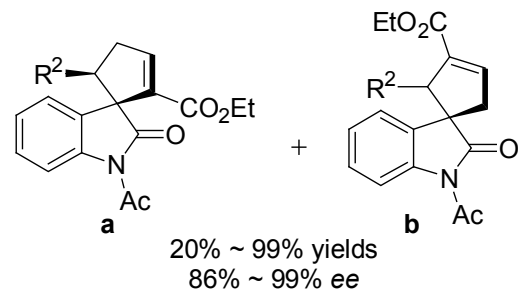

径: 一是香豆素衍生物直接与联烯酸酯发生 $[3+2]$ 环加 成得到目标产物(Eq. 26); 二是通过 $[3+2]$ 环加成得到关 键中间体，随后环合得到目标产物(Scheme 8). 两者目 标产物都取得了较好的收率和对映选择性. 


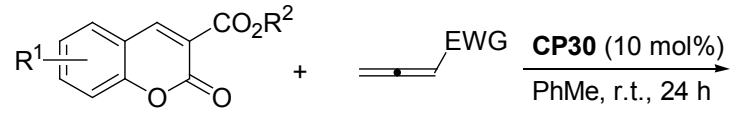

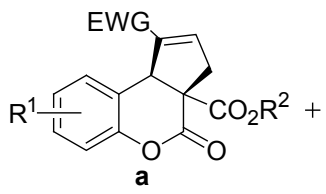

$45 \% \sim 84 \%$ yields $53 \% \sim 76 \%$ ee

$\mathrm{R}^{1}=\mathrm{H}, 7-\mathrm{MeO}, 8-\mathrm{Br}$, etc.

$\mathrm{R}^{2}=\mathrm{Me}, \mathrm{Et}, \mathrm{Cy}$

$\mathrm{EWG}=\mathrm{CO}_{2} \mathrm{Et}, \mathrm{CO}_{2} \mathrm{Bn}, \mathrm{P}(\mathrm{O})(\mathrm{OEt})_{2}$

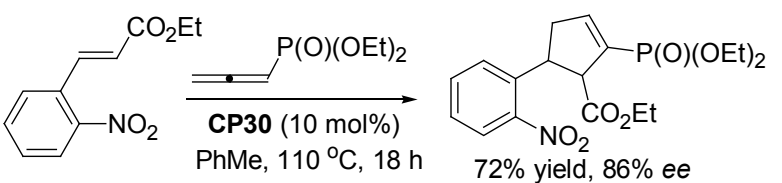

${ }_{80}^{\circ} \mathrm{C}$

Scheme 8

手性单膦催化剂也可催化联烯酸酯与亚胺的 [3+2] 环加成反应. 2007 年, Marinetti 等 ${ }^{\left[{ }^{[3]}\right]}$ 报道了催化剂 CP29, 该催化剂可促进 2-芳基-3-二氢吡咯类化合物的合成, 产物 ee 值可达 $80 \%$ (Eq. 27).

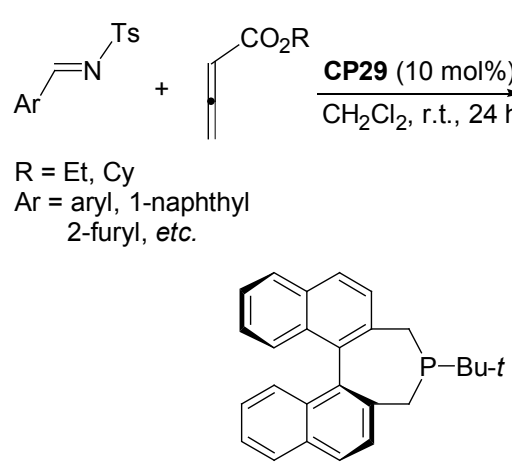

CP29

2012 年, Kwon 等 ${ }^{[44]}$ 报道通过环状手性单膦催化剂 CP31 催化联烯酸酯和膦酰亚胺的 $[3+2]$ 环加成反应, 制得中间体多取代环伐烯衍生物, 收率和 $e e$ 值分别为 93\%和 99\%, 再经 13 步反应, 可合成天然产物 $(+)-$ ibophyllidine (Scheme 9).

MBH 加成物也可参与分子内的环合反应. 2010 年 Tang 和 Zhou 等 ${ }^{[45]}$ 用手性单膦催化剂 CP32 催化分子内 MBH 加成物与活性烯烃的 $[3+2]$ 环加成反应(Eq. 28),<smiles>O=C(O)n1cc(/C=N/[Te])c2ccccc21</smiles>

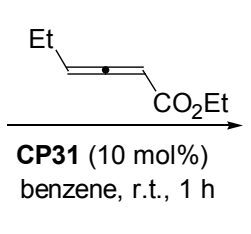<smiles>CCOC(=O)C1=C[C@@H](CC)C([As])[C@H]1c1cn(C(=O)OCc2ccccc2)c2ccccc12</smiles>

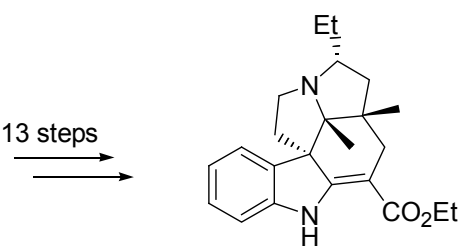

$93 \%$ yield, $99 \%$ ee

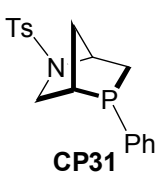

Scheme 9
在温和条件下, 得到具有连续 3 个手性中心的苯并双环 [4.3.0]化合物.
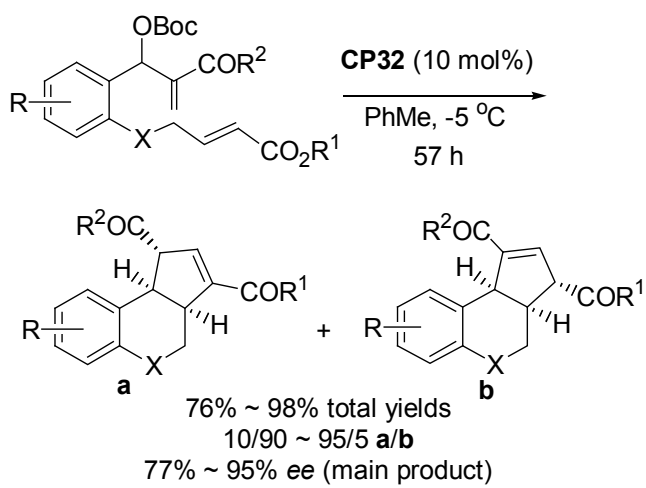

$\mathrm{R}=\mathrm{H}, 4-\mathrm{Br}, 4-\mathrm{OMe}$, etc.; $\mathrm{R}^{1}=\mathrm{OMe}, \mathrm{OEt}, \mathrm{Me} ; \mathrm{R}^{2}=\mathrm{OMe}, \mathrm{OEt}, \mathrm{Me}$; $\mathrm{X}=\mathrm{O}, \mathrm{C}$<smiles>COc1cc([N+](=O)[O-])cc(P(Cc2ccccc2)Cc2cccc3c2C2(CCc4ccccc42)CC3)c1</smiles>

\subsection{2 手性双膦催化剂}

2007 年 Wallace 等 ${ }^{[46]}$ 首次报道手性双膦催化剂 CP33 催化联烯酸酯与不饱和烯烃的 $[3+2]$ 环加成反应 (Eq. 29), 得到了具有中等到良好收率和 $e e$ 值的螺环酮 类化合物.

2009 年, Loh 等 ${ }^{[47]}$ 报道了手性双膦催化剂催化 $\alpha$ 位 三甲基硅烷取代的联烯酸酯与缺电子烯烃的 $[3+2]$ 环加 成反应，产物取得了良好收率和 $e e$ 值(Eq. 30). 研究表 明，联烯酸酯的 $\alpha$ 位引入三甲基硅烷是得到目标产物的 关键因素, 这可能是由于位阻的影响抑制了 $[4+2]$ 的自 

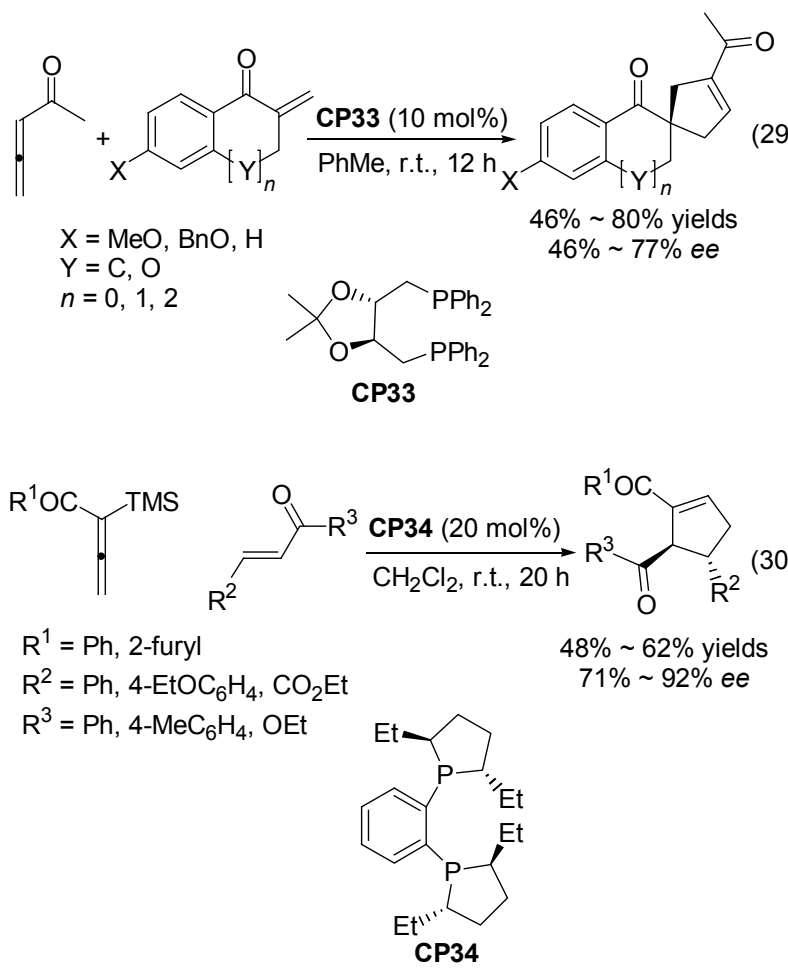

身缩合反应. 此外与一般的联烯酸酯相比, 该反应更有 利于 $\gamma$-产物的形成.

2010 年, Loh 等 ${ }^{[88]}$ 又报道了手性双膦催化剂催化不 同反应底物的 $[3+2]$ 环加成反应(Eq. 31 ), 得到了具有多 手性中心的多官能团环戊烯衍生物, 产物的收率和立体 选择性均较高.

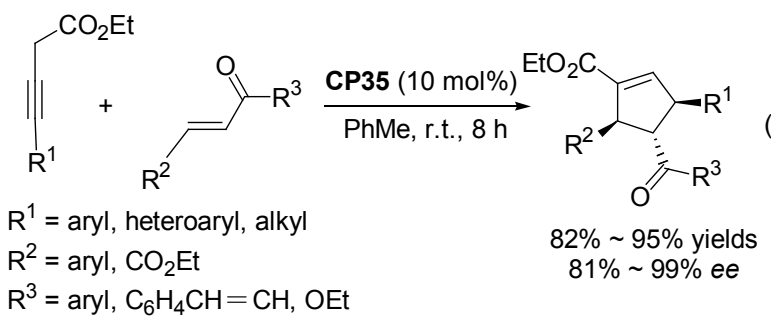<smiles>COc1ccccc1P(CCP(c1ccccc1)c1ccccc1OC)c1ccccc1</smiles>

2006 年, Marinetti 等 ${ }^{[49]}$ 首次报道了环番衍生的手性 双膦催化剂 CP36 催化不对称联烯酸酯与亚胺的 [3+2] 环加成反应, 得到了 3-芳基-2-二氢吡咯类化合物, 但收 率和 $e e$ 值均较低(Eq. 32).

2011 年, Barbas 等 ${ }^{[50]}$ 报道了手性双膦催化剂催化 MBH 加成物与活性烯烃的 $[3+2]$ 环加成反应, 合成具 有高对映选择性的螺环戊烷吲哚酮类化合物(Eq. 33),
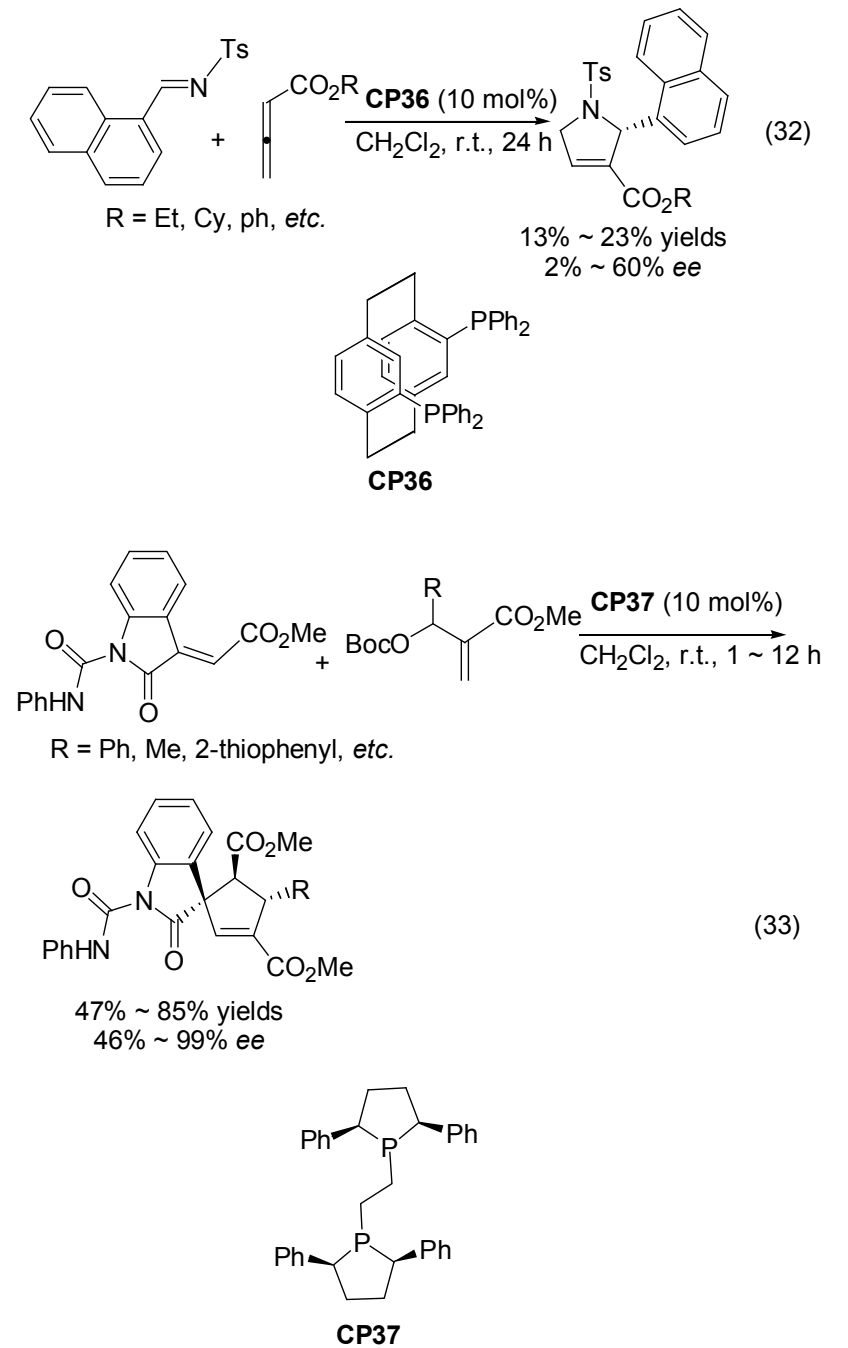

这为构建天然产物和候选药物中广泛存在的螺环戊烷 吲哚酮骨架提供了一条简单高效的途径.

2012 年, Liu 等 ${ }^{[51]}$ 报道了手性双膦催化剂催化 $N$-苯 基马来酰亚胺与 $\mathrm{MBH}$ 加成物的 $[3+2]$ 环加成反应(Eq. 34). 该反应的特点是一步构建了 3 个手性中心, 得到了 高收率和高对映选择性的螺环戊烷吲哚酩类化合物.

\subsection{3 双功能手性膦催化剂}

2007 年, Miller 等 ${ }^{[52]}$ 报道了 $\alpha$-氨基酸衍生的双功能 手性膦催化 $[3+2]$ 环加成反应，以 $95 \%$ 收率和 $80 \%$ 的 $e e$ 值(Eq. 35)获得目标产物. 在这一体系中, 反应底物与催 化剂通过 $\mathrm{P}, \mathrm{O}$ 原子相互作用和分子内的氢键形成稳定 的中间过渡态 $\mathbf{A}$, 从而来控制反应的立体选择性 (Scheme 10).

2010 年, Zhao 等 ${ }^{[53]}$ 报道了 $\alpha$-氨基酸衍生的双功能 手性膦高效催化联烯酸酯与活化烯烃的 $[3+2]$ 环加成反 应(Eq. 36). 在温和条件下, 得到目标产物的收率为 $79 \% \sim 99 \%$, ee 值为 $80 \% \sim 99 \%$. 与 Marinetti 的研究工作 相比，该反应拓展了反应底物，所得产物的收率和对映 


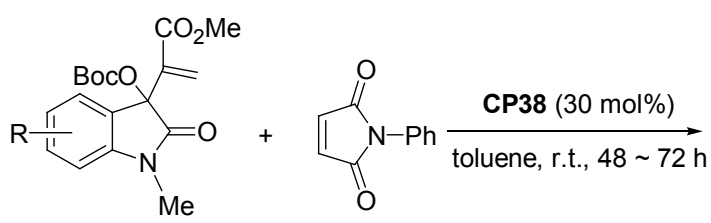

$\mathrm{R}=\mathrm{H}, 5-\mathrm{F}, 5-\mathrm{OMe}$, etc.<smiles>[R][R]c1ccccc1C12C(=O)N(C)c3ccccc3C1C1C(=O)N(c3ccccc3)C(=O)C12</smiles>

$40 \% \sim 84 \%$ yields $88 \% \sim 99 \%$ ee<smiles>[Y6]C1CCC(C)P1c1ccccc1P1C(C)CCC1C</smiles>

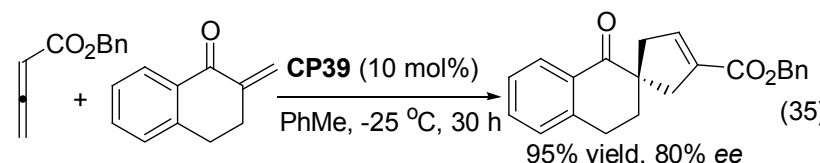<smiles></smiles><smiles>COC(=O)[C@@H]1Cc2ccccc2P(c2ccccc2)[C@H]1N(C(=O)OCc1ccccc1)P(c1ccccc1)c1ccccc1</smiles>

Proposed transition state $\mathbf{A}$

Scheme 10

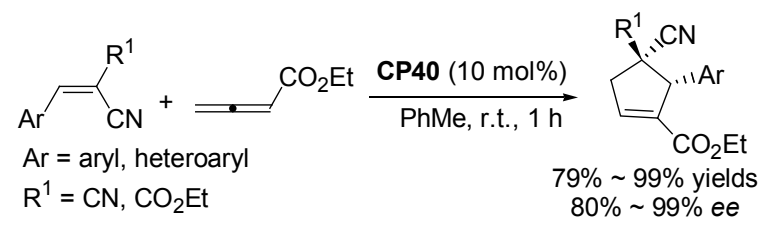<smiles>CCCC(C)C(Cc1ccccc1)NC(=O)c1cc(C(F)(F)F)cc(C(F)(F)F)c1</smiles>

选择性也有一定的提高, 然而该反应体系并不适用于脂 肪醛衍生的活性烯烃.

2011 年, $\mathrm{Lu}$ 等 ${ }^{[54 \mathrm{a}]}$ 报道了缩二氨酸衍生的双功能手 性膦催化 $\beta$-取代的丙烯酸酯与联烯酸酯的 $[3+2]$ 环加成

反应(Eq. 37). 研究表明，底物丙烯酸酯中大基团叔丁基 和催化剂中的大位阻基团氨基甲酸酯抑制了 $\gamma$-结构的 形成，从而提高了区域选择性. 同年， $\mathrm{Lu}$ 等 ${ }^{[54 \mathrm{~b}]}$ 首次将 3,5-二甲基- $1 H$-吡唑衍生的丙烯酰胺作为反应底物, 产 物具有较好收率和中等 $e e$ 值(Eq. 38). 2012 年, $\mathrm{Lu}$ 和 Shi 等 $^{[54 \mathrm{c}]}$ 又将不同取代的马来酰亚胺作为底物, 在催化剂 CP41 的催化下，反应得到的目标产物有 $76 \%$ \% $4 \%$ 的 收率和 $38 \% \sim 95 \%$ 的 $e e$ 值(Eq. 39).

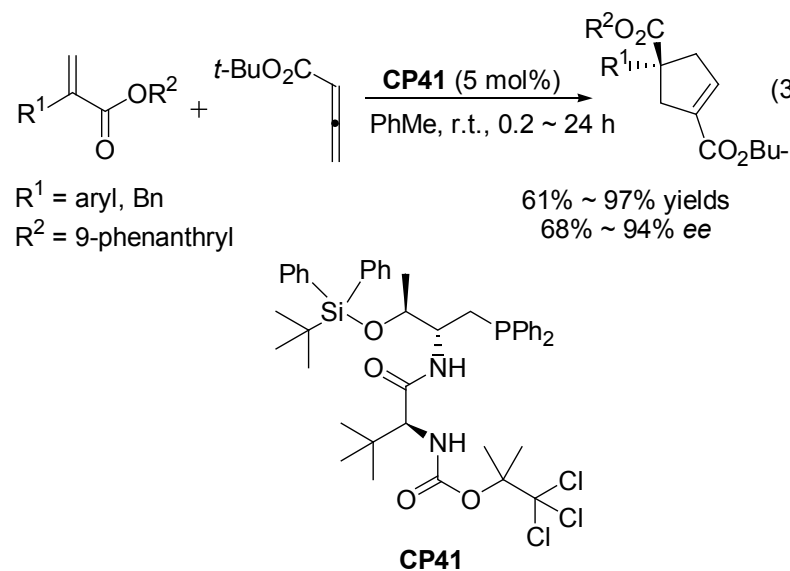

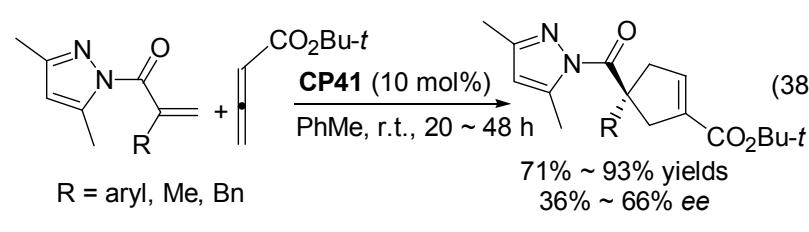

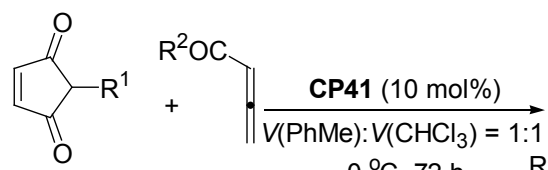
$0{ }^{\circ} \mathrm{C}, 72 \mathrm{~h} \quad \mathrm{R}^{2} \mathrm{OC} \mathrm{H}$ $\mathrm{R}^{1}=$ aryl, $\mathrm{Bn}, \mathrm{Me}$, etc. $\mathrm{R}^{2}=\mathrm{OEt}, \mathrm{OBn}, \mathrm{Me}$, etc.

$76 \% \sim 94 \%$ yields $38 \% \sim 95 \%$ ee

双功能手性膦催化剂也可以催化联烯酸酯与亚胺 的[3+2]环加成反应. 2008 年 Jacobsen 等 $^{[55]}$ 利用环已基 衍生的手性膦硫脲催化剂促进联烯酸酯和膦酰亚胺的 $[3+2]$ 环加成反应(Eq. 40), 得到目标产物的收率为 68\% 90\%, ee 值为 94\% 98\%, 但其反应速率要比磺酰

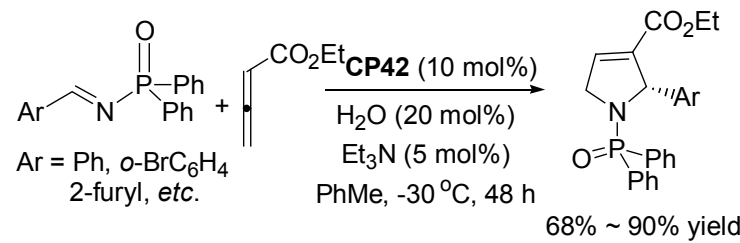<smiles>CC(C)(C)OC(=O)c1ccccc1</smiles>
$94 \% \sim 98 \%$ ee

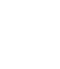


亚胺参与的环加成反应要慢.

2012 年, $\mathrm{Lu}$ 等 ${ }^{[56]}$ 报道了缩二氨酸衍生的双功能手 性膦催化联烯酸酯和膦酰亚胺的 $[3+2]$ 环加成反应, 得 到的目标产物可进一步转化为天然产物 $(+)$-trachelanthamidine (Scheme 11).

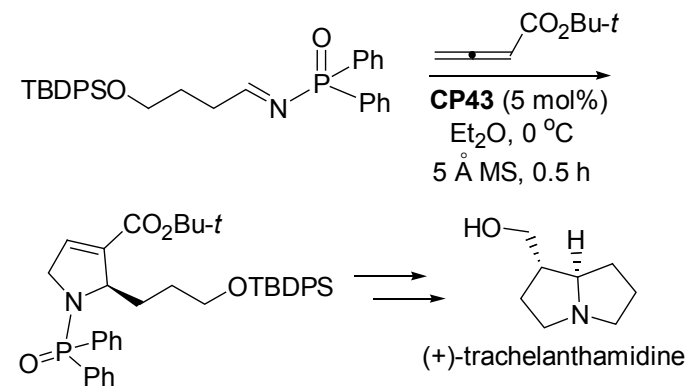

$82 \%$ yield, $96 \%$ ee<smiles>CC(C)C(NC(=O)[C@H](NC(=O)OCc1ccccc1)[C@H](C)OC(C)(C)C)C(=O)O</smiles>

Scheme 11

当然 $\mathrm{MBH}$ 加成物也可作为反应底物. 2011 年, $\mathrm{Lu}$ 等 ${ }^{[57]}$ 也报道了 $L$-苏氨酸衍生的双功能手性膦催化 $[3+2]$ 环加成反应，合成具有高对映选择性的螺环戌烷吲哚酥 类化合物, 取得了较高的收率和对映选择性(Eq. 41).

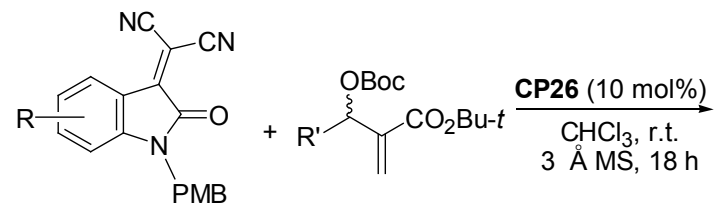

$\mathrm{R}=\mathrm{H}, \mathrm{Me}, \mathrm{Cl}, \mathrm{F}$

$\mathrm{R}^{\prime}=$ aryl, $\mathrm{CO}_{2} \mathrm{Et}$, 3-furyl, etc

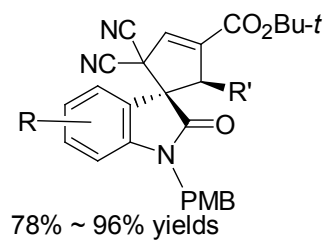

$65 \% \sim 99 \%$ ee<smiles>CC(O[SbH])C(CPc1ccccc1)NC(=S)Nc1ccc(F)cc1</smiles>

最近, Shi 等 ${ }^{[58]}$ 报道了 $L$-结氨酸衍生的双功能手性 膦催化 $\mathrm{MBH}$ 加成物与活性烯烃的 [3+2]环加成反应 (Eq. 42), 尽管活性烯烃不同, 但都得到了较高的收率和 优异的对映选择性. 同年, $\mathrm{Lu}$ 等 ${ }^{[59]}$ 也报道了缩二酸衍生 的双功能手性膦催化该反应 (Eq. 43). 研究表明, 与

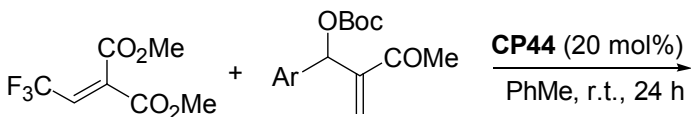

$\mathrm{Ar}=\mathrm{C}_{6} \mathrm{H}_{5}, 4-\mathrm{FC}_{6} \mathrm{H}_{4}, 4-\mathrm{CNC}_{6} \mathrm{H}_{4}$, etc.<smiles>CC(=O)C1=C([17F])C(C(C)=O)(C(C)=O)[C@H](C(F)(F)F)[C@H]1Br</smiles>

$57 \% \sim 99 \%$ yields $80 \% \sim 96 \%$ ee<smiles>S=C(NC(Cc1ccccc1)c1ccccc1)N(Cc1ccccc1)c1ccccc1</smiles>

CP44

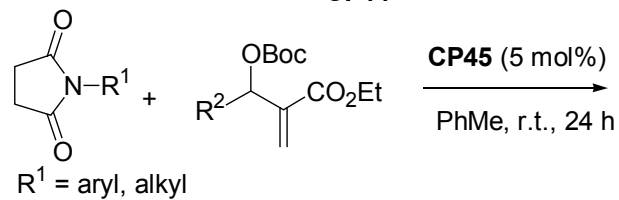
$\mathrm{R}^{2}=\mathrm{H}$, aryl, 2-furyl, etc<smiles>[R]C1C(C(=O)OC)=C[C@H]2C(=O)N([R])C(=O)[C@H]12</smiles><smiles>CC(C)C(Cc1ccccc1)C(=O)NC(C(=O)OC(C)(C)C)C(C)C</smiles>

CP44 相比, 5\% mol 的 CP45 即可催化 $[3+2]$ 环加成反应.

\section{$3.3[4+2]$ 环加成反应}

2003 年, Kwon 等 ${ }^{[60]}$ 首次报道了有机膦催化的磺酰 亚胺与取代的联烯酸酯 $[4+2]$ 环加成反应, 并且提出了 反应的可能机理(Scheme 12).

2005 年, $\mathrm{Fu}$ 等 ${ }^{[61]}$ 报道了手性膦催化磺酰亚胺与取 代联烯酸酯的 $[4+2]$ 环加成反应(Eq. 44), 取得了较高的 收率和对映选择性, 且反应产物可以进一步转化为一些 重要天然产物的骨架结构(Scheme 13).

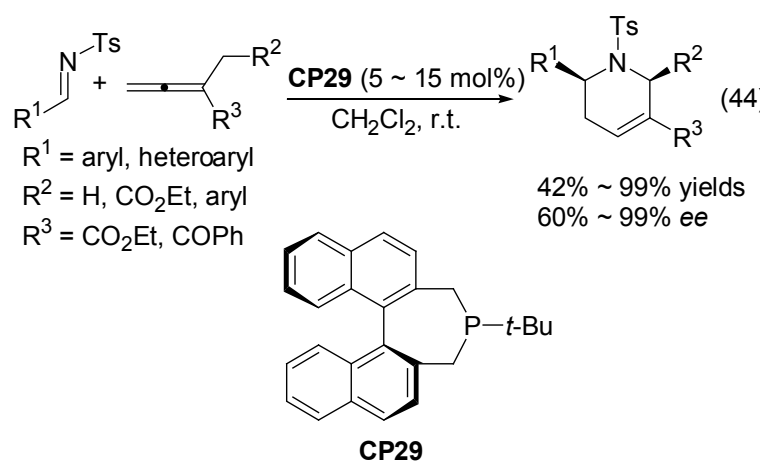




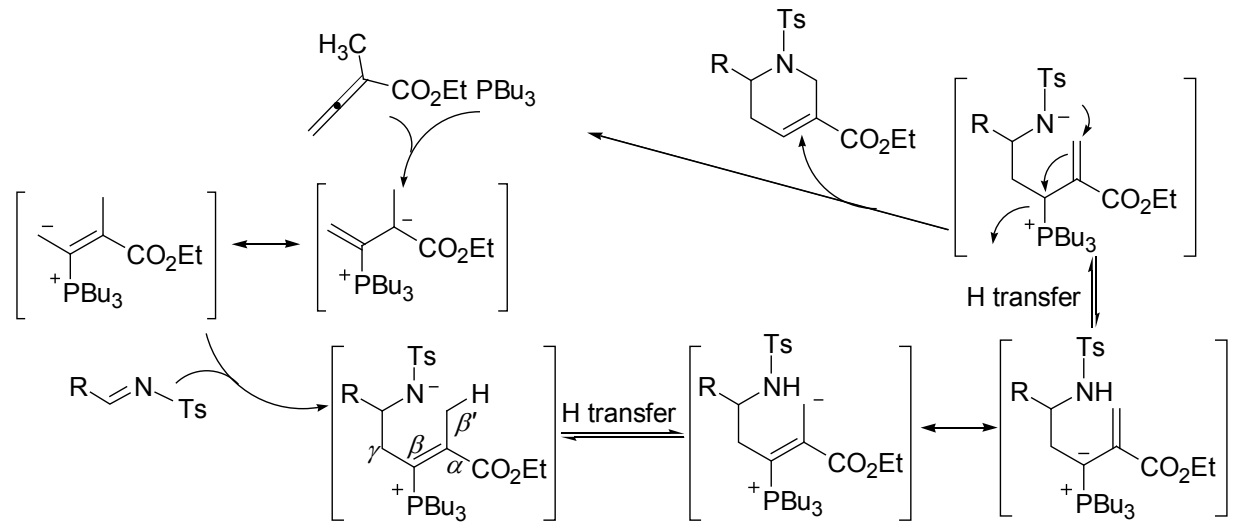

Scheme 12
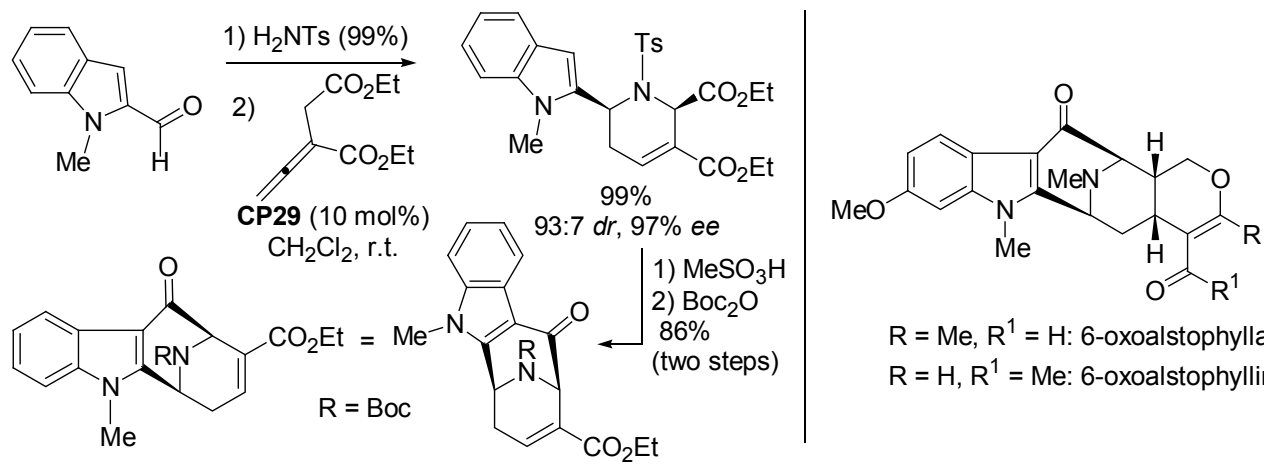

$R=M e, R^{1}=H:$ 6-oxoalstophyllal

$R=H, R^{1}=$ Me: 6-oxoalstophylline

Scheme 13

2011 年, Zhao 等 ${ }^{[62]}$ 报道了双功能手性膦催化磺酰 亚胺与取代的联烯酸酯 $[4+2]$ 环加成反应(Eq. 45). 在温 和条件下, 得到具有光学活性的四氢吡啶衍生物, 收率 可达 $98 \%$, ee 值可达 $96 \%$. 但当 $\mathrm{R}^{2}=\mathrm{H}$ 时, 反应不能进 行, 可能原因是在反应过程中形成的阴离子稳定性较 弱.

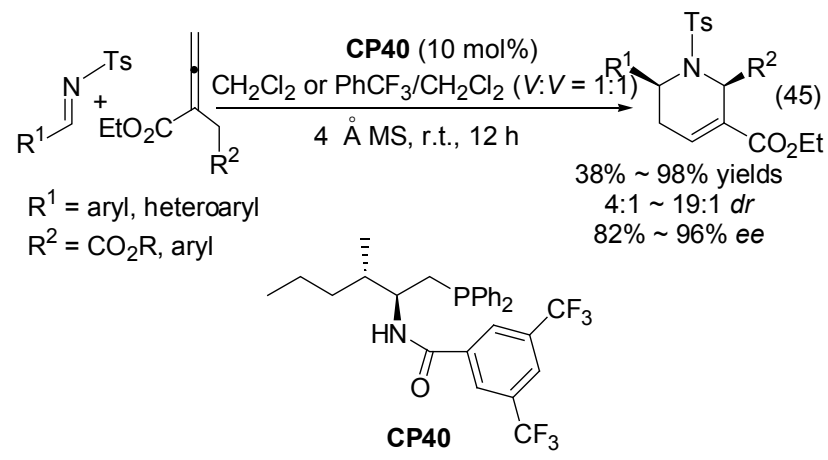

2012 年, $\mathrm{Lu}$ 等 ${ }^{[63]}$ 又对反应底物进行了拓展, 首次用 $L$-苏氨酸衍生的双功能手性膦催化活化烯烃与 $\alpha$ 取代联 烯酸酯的[4+2]环加成反应(Eq. 46), 取得了良好的收率 以及 $d r$ 值和 $e e$ 值. 目标产物 3-螺环已烯-2-吲哚酮结构 是广泛存在天然产物中的重要生物分子片段, 该方法为 构建该重要生物分子片段提供了一条有效的途径 (Scheme 14).

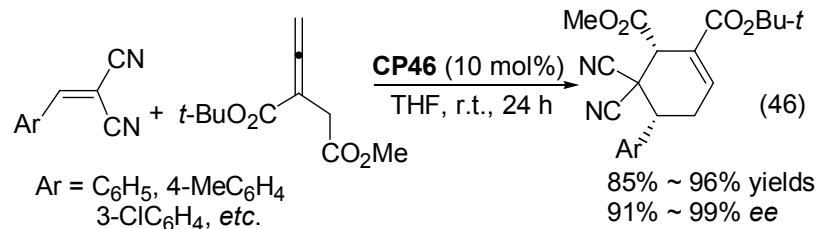<smiles>CC(C)OC(C)C(Cc1ccccc1)NC(=O)c1cc(C(F)(F)F)cc(C(F)(F)F)c1</smiles>

2012 年, Chi 等 ${ }^{[64]}$ 首次报道了氨基酸衍生的双功能 手性膦催化活化丙烯酸酯与 $\alpha, \beta$-不饱和亚胺的分子内 $[4+2]$ 环加成反应(Eq. 47), 得到具有优异对映选择性的 氮杂环产物. 并且该类产物可进一步转化为含手性哌啶 的稠环化合物.

同年, Zhong 等 ${ }^{[65]}$ 报道了 $L$-亮氨酸衍生的双功能手 性膦催化烯酮与 $N$-磺酰-1-氮杂-1,3-二烯的 $[4+2]$ 环加 成反应(Eq. 48), 巧妙地将分子间的交叉 aza-RauhutCurrie 反应与其后续的分子内环化反应结合在一起，从 而提供了一条高效制备具有强生物活性和多取代手性 的四氢吡啶类衍生物的捷径. 


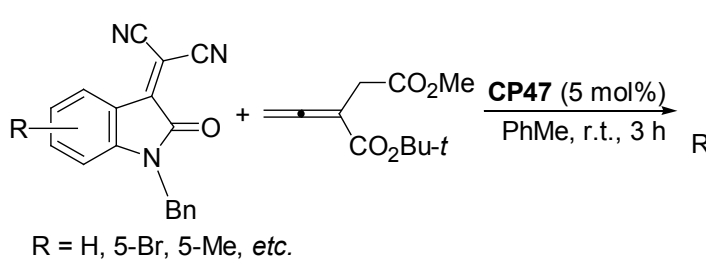

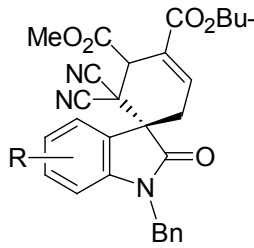

$91 \% \sim 96 \%$ yields 95:5 99:1 dr $89 \% \sim 93 \%$ ee

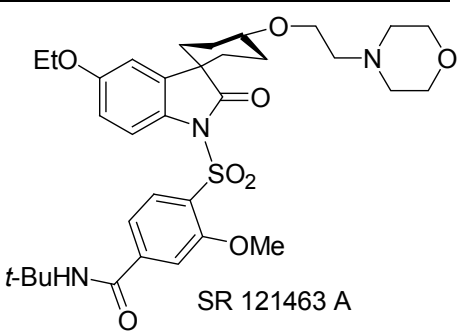

Scheme 14

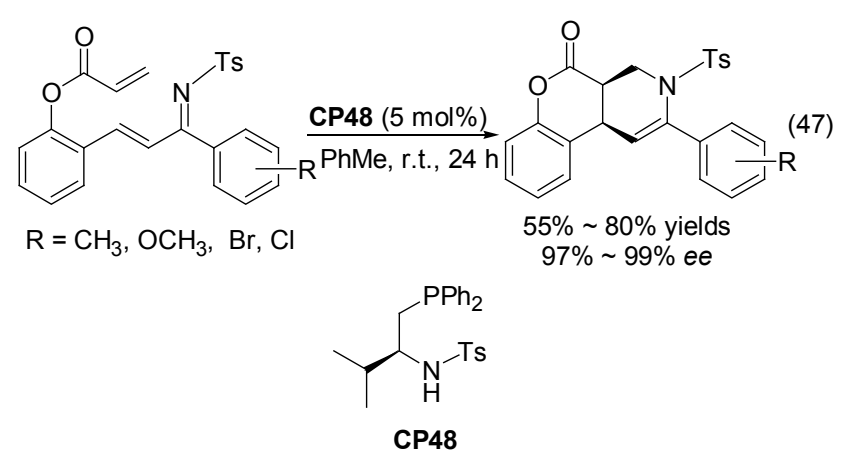

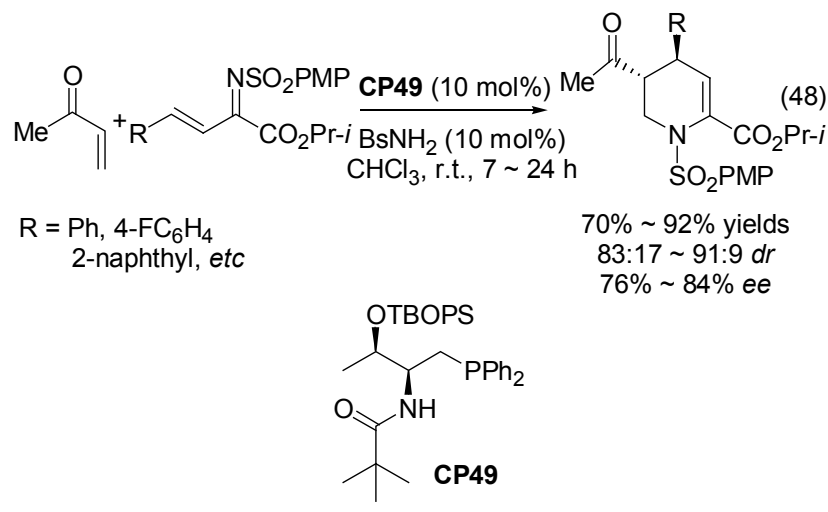

\section{4 酯化反应}

有机膦催化醇与醋酤的酯化反应, 首先是有机磷与 醋酐形成磷酰基羧酸酯中间体，该中间体再与醇形成目 标产物 ${ }^{[66 a]}$. 依据此机理, 1996 年 Vedejs 等 ${ }^{[66 b]}$ 首次报道 了手性膦催化仲醇的不对称酯化反应(Eq. 49).

同时也可利用手性膦催化剂 CP51 对芳基 ${ }^{[67 a]}$ 和烯 丙基 ${ }^{[67 b]}$ 取代的仲醇进行动力学拆分(Eq. 50), 且酰化试 剂异丁酸酐对反应的对映选择性要比醋酐和苯甲酸酐 更好. 在温和条件下, 手性膦催化剂 CP51 与酶催化反

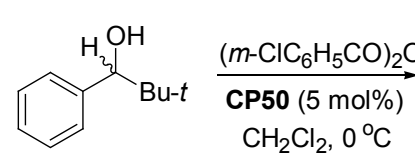<smiles>O=C(O[C@@H](Br)c1ccccc1)c1ccccc1</smiles><smiles>[R6]C(C)(C)C1CC[C@@H](C)P1c1ccccc1</smiles>

应得到产物的对映选择性相当，尤其是邻位取代的芳基 底物. 然而手性膦催化剂 CP51 对空气不稳定, 之后又 制备出了在空气中稳定、易处理的四氟硼烷膦盐催化 剂 $^{[67 \mathrm{c}]}$.

$$
\begin{aligned}
& \mathrm{R}^{1}=\mathrm{Ph}, 1 \text {-naphthyl, mesityl, etc. } \\
& \mathrm{R}^{2}=\mathrm{Me}, n \text { - } \mathrm{Bu}, i-\mathrm{Pr}
\end{aligned}
$$

除了简单的动力学拆分, Vedejs 和 Rozners ${ }^{[68]}$ 用两 种具有互补立体选择性的手性催化剂(手性膦 CP51 和 脂肪酶)对芳基取代的仲醇进行平行动力学拆分, 使反 应底物的两个异构体在竞争反应中保持最适的 $1: 1$ 比 例, 从而能得到具有优异 $e e$ 值和转化率的两个对映异 构体产物.

2004 年, Vedejs 等 ${ }^{[69]}$ 又报道了利用单环或双环手性 膦催化内消旋二苯基乙二醇的苯甲酰化反应(Eq. 51), 而这个过程比简单醇的动力学拆分效率要低. 在相应的 

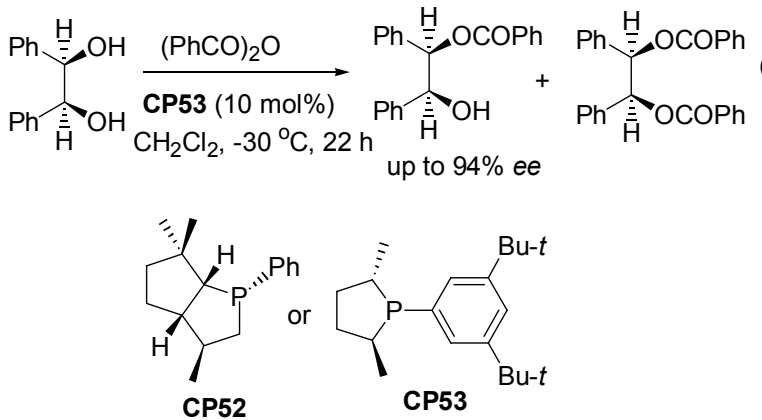

反应条件下，使用催化剂 CP52 催化的反应得到的对映 其催化活性较低, 催化剂的用量较大.

与前面不同, 2003 年 Vedejs 等 ${ }^{[70]}$ 报道了一类手性膦 催化的酰基迁移反应(Eq. 52). 具有高度亲核性的手性 膦催化剂 CP51 能够高效催化该反应, 得到产物的对映 选择性超过 $90 \%$, 且与手性吡啶衍生物催化剂相比, 催 化剂 CP51 适用的反应底物范围更广.

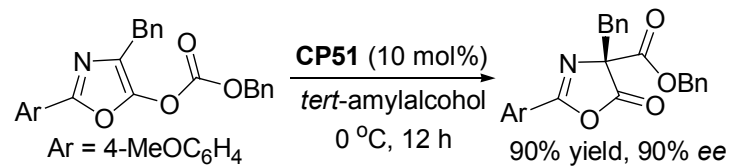

2009 年, $\mathrm{Fu}$ 等 ${ }^{[71 \mathrm{a}]}$ 首次用手性膦催化硝基甲烷与联 烯酰胺之间的 $\gamma$-加成反应(Eq. 53). 研究表明, 在温和条 件下, 可获得高收率和高立体选择性的目标产物, 其可

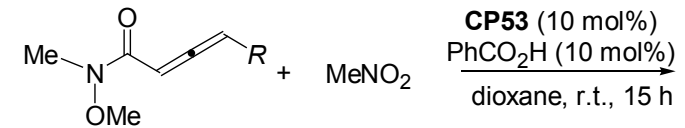

$\mathrm{R}=\mathrm{Me}, n-\mathrm{Pr},\left(\mathrm{CH}_{2}\right)_{3} \mathrm{CO}_{2} \mathrm{Me}$, etc.<smiles>[R]C(C=CC(=O)N(C)OC)C[N+](=O)[O-]</smiles>

$57 \% \sim 94 \%$ yields $81 \% \sim 97 \%$ ee<smiles>CCN1CC2=CC=c3ccccc3=C(c3cccc4ccccc34)C2CC1(C)C</smiles>

同年, $\mathrm{Fu}$ 等 ${ }^{[71 b]}$ 报道了手性膦催化一系列羟基-2-炔 酸酯衍生物发生分子内的 $\gamma$-亲核加成环合反应，转化成 具有高对映选择性的含氧杂环化合物(Eq. 54), 可高效 制备四氢呋喃、四氢吡喃、四氢苯并吡喃等衍生物. 选择性最好, 但产生了副产物. 而使用催化剂 CP53 时,

\section{$5 y$-亲核加成反应} 能的机理如 Scheme 15 所示.
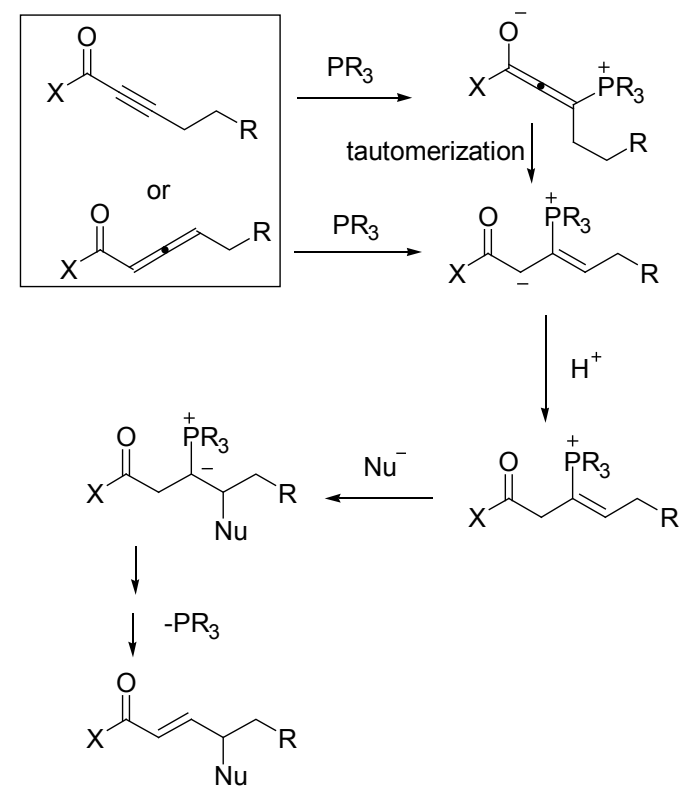

\section{Scheme 15}
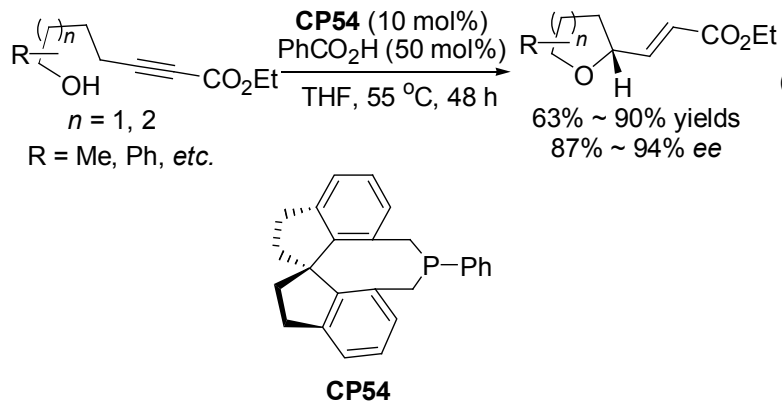

之后 $\mathrm{Fu}$ 等 ${ }^{[70 \mathrm{c}]}$ 尝试了在手性膦催化剂 CP55 催化下, 各种联烯酸酯与丙二酸酯之间的 $\gamma$-亲核加成反应，得到 产物的收率为 $65 \% \sim 94 \%$, ee 值为 $85 \% \sim 94 \%$ (Eq. 55).
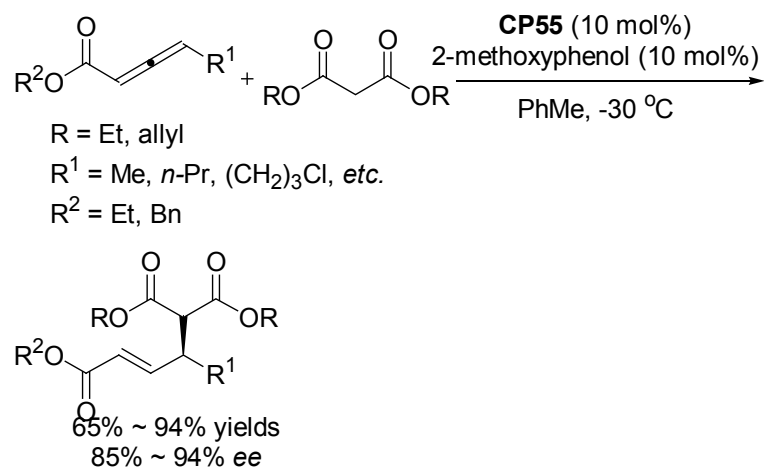
和对映选择性(Eq. 56). 而在相同的条件下以苯硫酚为 亲核试剂时, 产物只得到 $9 \%$ 的收率和 $70 \%$ 的 $e e$ 值. 考 虑到芳基硫酚的重要性, 在 2011 年 $\mathrm{Fu}$ 等 ${ }^{[72 b]}$ 又报道了以 芳基硫酚为亲核试剂的 $\gamma$ 加成反应 (Eq. 57), 可得到收 率 $58 \% \sim 81 \%$ 和 $e e$ 值 $81 \% \sim 95 \%$ 的目标产物.
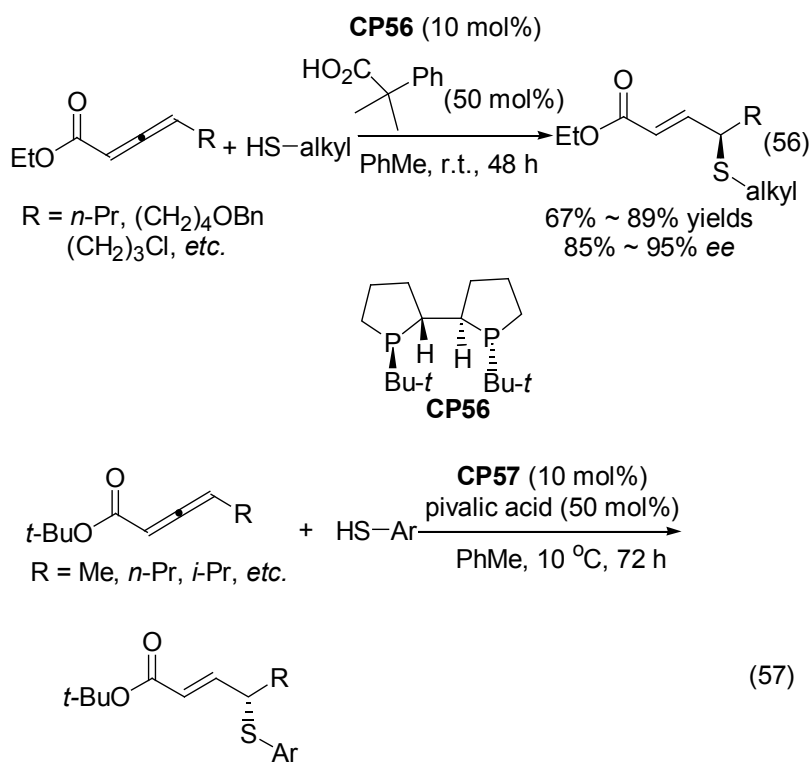

$58 \% \sim 81 \%$ yields $81 \% \sim 95 \%$ ee

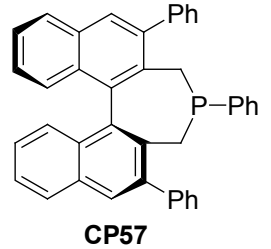

\section{6 其它反应}

手性膦催化剂除了催化上述有机反应外, 还可催化 其它有机反应. 2007 年 Gladysz 等 ${ }^{[73]}$ 报道了手性膦催化 Rauhut-Currier 反应(Eq. 58), 得到的产物具有较好的收 率和中等 $e e$ 值.

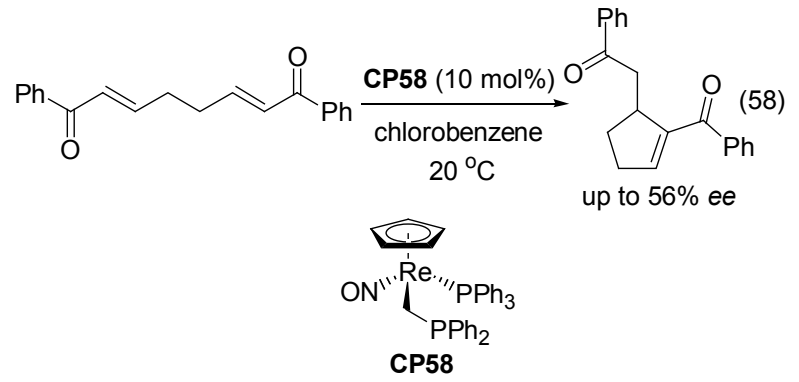

之后, $\mathrm{Wu}$ 等 ${ }^{[74]}$ 报道了 $L$-颎氨酸衍生的双功能手性 膦硫脲催化剂催化分子内的 Rauhut-Currier 反应(Eq. 59), 取得了很好的收率和优异的对映选择性.

2009 年, Kerrigan 等 ${ }^{[75]}$ 报道了用手性膦催化剂 CP27 催化乙烯酠的二聚反应(Eq. 60), 得到的 $Z$ 式二聚

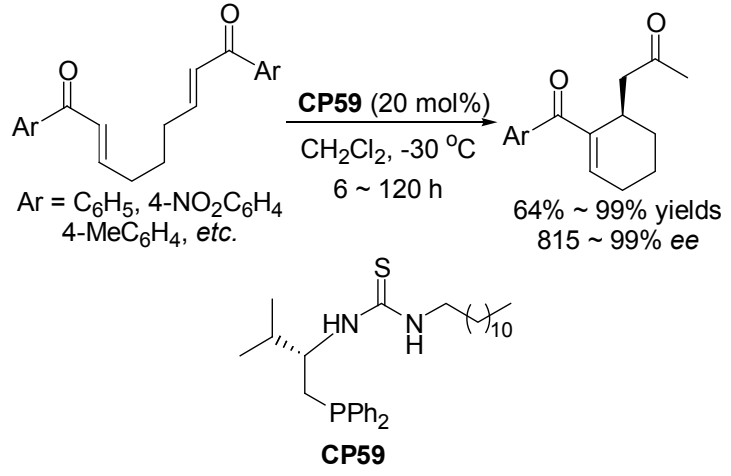

产物有 $80 \%$ 的 $e e$ 值.

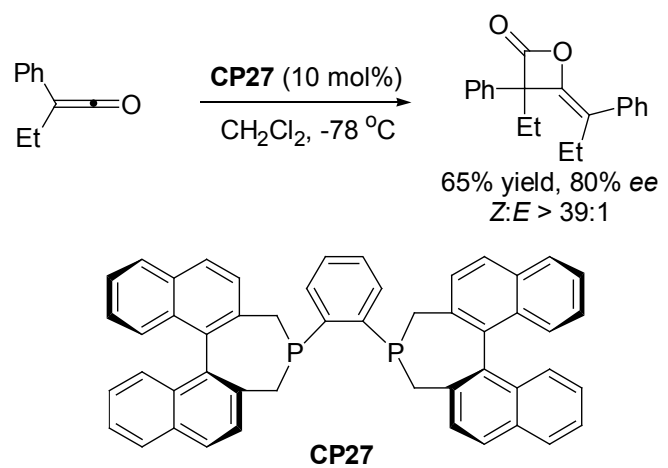

手性膦催化剂还可催化氮杂环丙烷的开环反应. 2009 年 Jacobsen 等 ${ }^{[76]}$ 利用手性膦硫脲催化该反应(Eq. $61)$, 得到的开环产物都具有较高的 $e e$ 值.
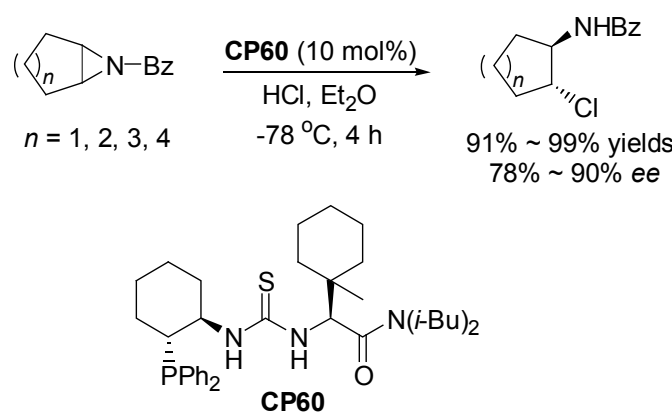

\section{7 结论与展望}

本文主要综述了近年来手性膦小分子催化剂催化 不对称反应的研究进展, 其催化反应的主要特点是反应 条件简单、温和, 催化剂催化活性较高以及对环境友好, 原料价格低廉，反应体系无重金属残留，符合绿色化学 的要求, 具有广阔的应用前景. 但其也存在一些缺点: 反应的催化剂用量相对较多, 某些反应催化效率不如金 属催化剂, 这些问题都亟待解决. 所以要突破传统思路 进行新型手性膦催化剂的设计与实验，提出和发展手性 催化的一些新概念和新方法, 为手性催化研究提供理论 指导, 也为将实验室的科学研究走向工业应用提供理论 基础. 


\section{References}

[1] (a) Yao, D.-M.; Tian, F.-T.; Zhang, W.-B. Chin. J. Org. Chem. 2011, 31, 505 (in Chinese).

(姚冬梅, 田丰涛, 张万斌, 有机化学, 2011,31, 505.)

(b) Yu, H.-W.; Guan, M.; Tong, Q.-S.; Jia, L.; Jin, Z.-L.; Shi, J.-C. Chin. J. Org. Chem. 2011, 31, 1100 (in Chinese).

(于宏伟, 官旻, 童庆松, 贾莉, 金子林, 施继成, 有机化学, 2011, 31, 1100.)

(c) Zhang, Y.; Yi, T.; Wang, K.; Fu, H.-Y.; Chen, H.; Li, R.-X. Chin. J. Org. Chem. 2012, 32, 790 (in Chinese).

(张愚, 易蹈, 王壁, 付海燕, 陈华, 李瑞祥, 有机化学, 2012, 32, 790.)

(d) Fernandez-Perez, H.; Etayo, P.; Panossian, A.; Vidal-Ferran, A. Chem. Rev. 2011, 111, 2119.

[2] Dalko, P. I.; Moisan, L. Angew. Chem., Int. Ed. 2004, 43, 5138.

[3] Fu, B.; Xiao, Y.-M.; Li, N. Chin. J. Org. Chem. 2006, 26, 899 (in Chinese).

(傅滨, 肖玉梅, 李楠, 有机化学, 2006, 26, 899.)

[4] Methot, J. L.; Roush, W. R. Adv. Synth. Catal. 2004, 346, 1035.

[5] Marinetti, A.; Voituriez, A. Synlett 2010, 174.

[6] Hayase, T.; Shibata, T.; Soai, K.; Wakatsuki, Y. Chem. Commun. 1998, 1271.

[7] (a) Shi, M.; Chen, L. H. Chem. Commun. 2003, 1310.

(b) Wei, Y.; Shi, M. Acc. Chem. Res. 2010, 43, 1005.

[8] Liu, Y. H.; Chen, L. H.; Shi, M. Adv. Synth. Catal. 2006, 348, 973

[9] Matsui, K.; Takizawa, S.; Sasai, H. Synlett 2006, 761.

[10] Ito, K.; Nishida, K.; Gotanda, T. Tetrahedron Lett. 2007, 48, 6147.

[11] (a) Shi, M.; Chen, L. H.; Teng, W. D. Adv. Synth. Catal. 2005, 347, 1781.

(b) Liu, Y. H.; Shi, M. Adv. Synth. Catal. 2008, 350, 122.

[12] (a) Shi, M.; Li, C. Q. Tetrahedron: Asymmetry 2005, 16, 1385.

(b) Lei, Z. Y.; Ma, G. N.; Shi. M. Eur. J. Org. Chem. 2008, 3817.

(c) Lei, Z. Y.; Liu, X. G.; Shi, M. Zhao, M. X. Tetrahedron: Asymmetry 2008, 19, 2058.

[13] (a) Shi, Y. L.; Shi, M. Adv. Synth. Catal. 2007, 349, 2129.

(b) Qi, M. J.; Ai, T.; Shi, M.; Li, G. G. Tetrahedron 2008, 64, 1181. (c) Guan, X. Y.; Jiang, Y. Q.; Shi, M. Eur. J. Org. Chem. 2008, 2150 .

[14] Garnier, J. M.; Anstiss, C.; Liu, F. Adv. Synth. Catal. 2009, 351, 331.

[15] Takizawa, S.; Inoue, N.; Hirata, S.; Sasai, H. Angew. Chem., Int. Ed. 2010, 49, 9725.

[16] Gong, J. J.; Yuan, K.; Wu, X. Y. Tetrahedron: Asymmetry 2009, 20, 2117.

[17] Zhong, F. R.; Wang, Y. Q.; Han, X. Y.; Huang, K. W.; Lu, Y. X. Org. Lett. 2011, 13, 1310.

[18] Han, X. Y.; Wang, Y. Q.; Zhong, F. R.; Lu, Y. X. Org. Biomol. Chem. 2011, 9, 6734.

[19] (a) Yuan, K.; Zhang, L.; Song, H. L.; Hu, Y. J.; Wu, X. Y. Tetrahedron Lett. 2008, 49, 6262.

(b) Yuan, K.; Song, H. L.; Hu, Y. J.; Wu, X. Y. Tetrahedron 2009, 65,8185 .

[20] Wang, C. C.; Wu, X. Y. Tetrahedron 2011, 67, 2974.

[21] (a) Galliford, C. V.; Scheidt, K. A. Angew. Chem., Int. Ed. 2007, 46, 8748. (b) Peddibhotla, S. Curr. Bioact. Compd. 2009, 5, 20.

[22] Qian, J. Y.; Wang, C. C.; Sha, F.; Wu, X. Y. RSC $A d v$. 2012, 2, 6042.

[23] Song, H. L.; Yuan, K.; Wu, X. Y. Chem. Commun. 2011, 47, 1012.

[24] Pereira, S. I.; Adrio, J.; Silva, A..; Carretero, J. C. J. Org. Chem. 2005, 70, 10175.
[25] Rios, R. Catal. Sci. Technol. 2012, 2, 267.

[26] (a) Cho, C. W.; Kong, J. R.; Krische, M. J. Org. Lett. 2004, 6, 1337. (b) Cho, C. W.; Krische, M. J. Angew. Chem., Int. Ed. 2004, 43, 6689.

[27] Zhang, T. Z.; Dai, L. X.; Hou, X. L. Tetrahedron: Asymmetry 2007, $18,1990$.

[28] Jiang, Y. Q.; Shi, Y. L.; Shi, M. J. Am. Chem. Soc. 2008, 130, 7202.

[29] Ma, G. N.; Cao, S. H.; Shi, M. Tetrahedron: Asymmetry 2009, 20, 1086.

[30] Yang, Y. L.; Pei, C. K.; Shi, M. Org. Biomol. Chem. 2011, 9, 3349.

[31] Deng, H. P.; Shi, M. Eur. J. Org. Chem. 2012, 183.

[32] Zhong, F. R.; Luo, J.; Chen, G. Y.; Dou, X. W.; Lu, X. Y. J. Am. Chem. Soc. 2012, 134, 10222.

[33] Mondal, M.; Ibrahim, A. A.; Wheeler, K. A.; Kerrigan, N. J. Org. Lett. 2010, 12, 1664.

[34] Zhao, Q. Y.; Lian, Z.; Wei, Y.; Shi, M. Chem. Commun. 2012, 48, 1724.

[35] Zhang, C. M.; Lu, X. Y. J. Org. Chem. 1995, 60, 2906.

[36] Zhu, G. X.; Chen, Z. G.; Jiang, Q. Z.; Xiao, D. M.; Cao, P.; Zhang, X. M. J. Am. Chem. Soc. 1997, 119, 3836.

[37] Wilson, J. E.; Fu, G. C. Angew. Chem., Int. Ed. 2006, 45, 1426.

[38] (a) Voituriez, A.; Panossian, A.; Fleury-Brégeot, N.; Retailleau, P.; Marinetti, A. J. Am. Chem. Soc. 2008, 130, 14030.

(b) Voituriez, A.; Panossian, A.; Fleury-Brégeot, N.; Retailleau, P.; Marinetti, A. Adv. Synth. Catal. 2009, 351, 1968.

[39] Pinto, N.; Neel, M.; Panossian, A.; Retailleau, P.; Frison, G.; Voituriez, A.; Marinetti, A. Chem. Eur. J. 2010, 16, 1033.

[40] Schuler, M.; Voituriez, A.; Marinetti, A. Tetrahedron: Asymmetry 2010, 21, 1569.

[41] Voituriez, A.; Pinto, N.; Neel, M.; Retailleau, P.; Marinetti, A. Chem. Eur. J. 2010, 16, 12541

[42] Neel, M.; Gouin, J.; Voituriez, A.; Marinetti, A. Synthesis 2011, 2003.

[43] Fleury-Brégeot, N.; Jean, L.; Retailleau, P.; Marinetti, A. Tetrahedron 2007, 63, 11920.

[44] Andrews, I. P.; Kwon, O. Chem. Sci. 2012, 3, 2510.

[45] Wang, Q. G.; Zhu, S. F.; Ye, L. W.; Zhou, C. Y.; Sun, X. L.; Tang, Y.; Zhou, Q. L. Adv. Synth. Catal. 2010, 352, 1914.

[46] Wallace, D. J.; Sidda, R. L.; Reamer, R. A. J. Org. Chem. 2007, 72, 1051.

[47] Sampath, M.; Loh, T. P. Chem. Commun. 2009, 1568.

[48] Sampath, M.; Loh, T. P. Chem. Sci. 2010, 1, 739.

[49] Jean, L.; Marinetti, A. Tetrahedron Lett. 2006, 47, 2141.

[50] Tan, B.; Candeias, N. R.; Barbas III, C. F. J. Am. Chem. Soc. 2011, 133, 4672.

[51] Wang, Y.; Liu, L.; Zhang, T.; Zhong, N. J.; Wang, D.; Chen, Y. J. J. Org. Chem. 2012, 77, 4143.

[52] Cowen, B. J.; Miller, S. J. J. Am. Chem. Soc. 2007, 129, 10988.

[53] Xiao, H.; Chai, Z.; Zheng, C. W.; Yang, Y. Q.; Liu, W.; Zhang, J. K.; Zhao, G. Angew. Chem. 2010, 122, 4569.

[54] (a) Han, X. Y.; Wang, Y. Q.; Zhong, F. R.; Lu, Y. X. J. Am. Chem. Soc. 2011, 133, 1726.

(b) Han, X. Y.; Wang, S. X.; Zhong, F. R.; Lu, Y. X. Synthesis 2011, 1859.

(c) Zhao, Q. Y.; Han, X. Y.; Wei, Y.; Shi, M.; Lu, Y. X. Chem. Commun. 2012, 48, 970.

[55] Fang, Y. Q.; Jacobsen, E. N. J. Am. Chem. Soc. 2008, 130, 5660.

[56] [56] Han, X. Y.; Zhong, F. R.; Wang, Y. Q.; Lu, Y. X. Angew. Chem., Int. Ed. 2012, 51, 767.

[57] Zhong, F. R.; Han, X. Y.; Wang, Y. Q.; Lu, Y. X. Angew. Chem., Int. Ed. 2011, 50, 7837. 
[58] (a) Deng, H. P.; Wei, Y.; Shi, M. Adv. Synth. Catal. 2012, 354, 783. (b) Deng, H. P.; Wang, D.; Wei, Y.; Shi, M. Beilstein J. Org. Chem. 2012, 8, 1098.

[59] Zhong, F. R.; Chen, G. Y.; Han, X. Y.; Yao, W. J.; Lu, Y. X. Org. Lett. 2012, 14, 3764.

[60] Zhu, X. F.; Lan, J.; Kwon, O. J. Am. Chem. Soc. 2003, 125, 4716.

[61] Wurz, R. P.; Fu, G. C. J. Am. Chem. Soc. 2005, 127, 12234.

[62] Xiao, H.; Chai, Z.; Wang, H. F.; Wang, X. W.; Cao, D. D.; Liu, W.; Lu, Y. P.; Yang, Y. Q.; Zhao, G. Chem. Eur. J. 2011, 17, 10562.

[63] Zhong, F. R.; Han, X. Y.; Wang, Y. Q.; Lu, Y. X. Chem. Sci. 2012, $3,1231$.

[64] Jin, Z. C.; Yang, R. J.; Tiwari, B.; Ganguly, R.; Chi, Y. G. Org. Lett. 2012, 14, 3226.

[65] Shi, Z. G.; Yu, P. Y.; Loh, T. P.; Zhong, G. F. Angew. Chem., Int. Ed. 2012, 51, 1 .

[66] (a) Vedejs, E.; Diver, S. T. J. Am. Chem. Soc. 1993, 115, 3358.| (b) Vedejs, E.; Daugulis, O.; Diver, S. T. J. Org. Chem. 1996, 61, 430.

[67] (a) Vedejs, E.; Daugulis, O. J. Am. Chem. Soc. 1999, 121, 5813.

(b) Vedejs, E.; MacKay, J. A. Org. Lett. 2001, 3, 535. (c) MacKay, J. A.; Vedejs, E. J. Org. Chem. 2004, 69, 6934

[68] Vedejs, E.; Rozners, E. J. Am. Chem. Soc. 2001, 123, 2428.

[69] Vedejs, E.; Daugulis, O.; Tuttle, N. J. Org. Chem. 2004, 69, 1389.

[70] (a) Shaw, S. A.; Aleman, P.; Vedejs, E. J. Am. Chem. Soc. 2003, $125,13368$.

(b) Shaw, S. A.; Aleman, P.; Christy, J.; Kampf, J. W.; Va, P.; Vedejs, E. J. Am. Chem. Soc. 2006, 128, 925.

[71] (a) Smith, S. W.; Fu, G. C. J. Am. Chem. Soc. 2009, 131, 14231.

(b) Chung, Y. K.; Fu, G. C. Angew. Chem., Int. Ed. 2009, 48, 2225.

(c) Sinisi, R.; Sun, J. W.; Fu, G. C. Proc. Natl. Acad. Sci. U. S. A. 2010, 107, 20652.

[72] (a) Sun, J. W.; Fu, G. C. J. Am. Chem. Soc. 2010, 132, 4568. (b) Fujiwara, Y. J.; Sun, J. W.; Fu, G. C. Chem. Sci. 2011, 2, 2196.

[73] Seidel, F.; Gladysz, J. Synlett 2007, 986.

[74] Gong, J. J.; Li, T. Z.; Pan, K.; Wu, X. Y. Chem. Commun. 2011, 47, 1491.

[75] Ibrahim, A. A.; Harzmann, G. D.; Kerrigan, N. J. J. Org. Chem. 2009, 74, 1777.

[76] Mita, T.; Jacobsen, E. N. Synlett 2009, 1680.

(Zhao, X.) 